\title{
Paracrine Role for Somatostatin Interneurons in the Assembly of Perisomatic Inhibitory Synapses
}

\author{
Jianmin Su, ${ }^{1}$ Danielle Basso, ${ }^{1,2}$ Shivani Iyer, ${ }^{1,2}$ Kaiwen Su, ${ }^{1}$ Jessica Wei, ${ }^{1,3}$ and Michael A. Fox ${ }^{1-5}$ \\ ${ }^{1}$ Center for Neurobiology Research, Fralin Biomedical Research Institute at Virginia Tech Carilion, Roanoke, Virginia 24016, ${ }^{2}$ Department of \\ Biological Sciences, Virginia Tech, Blacksburg, Virginia 24061, ${ }^{3}$ neuroSURF Program, Fralin Biomedical Research Institute at Virginia Tech \\ Carilion, Roanoke, Virginia 24016, ${ }^{4}$ Department of Pediatrics, Virginia Tech Carilion School of Medicine, Roanoke, Virginia 24016, and ${ }^{5}$ School of \\ Neuroscience, Virginia Tech, Blacksburg, Virginia 24061
}

GABAergic interneurons represent a heterogenous group of cell types in neocortex that can be clustered based on developmental origin, morphology, physiology, and connectivity. Two abundant populations of cortical GABAergic interneurons include the low-threshold, somatostatin (SST)-expressing cells and the fast-spiking, parvalbumin (PV)-expressing cells. While $\mathrm{SST}^{+}$and $\mathrm{PV}^{+}$interneurons are both early born and migrate into the developing neocortex at similar times, $\mathrm{SST}^{+}$cells are incorporated into functional circuits prior to $\mathrm{PV}^{+}$cells. During this early period of neural development, $\mathrm{SST}^{+}$cells play critical roles in the assembly and maturation of other cortical circuits; however, the mechanisms underlying this process remain poorly understood. Here, using both sexes of conditional mutant mice, we discovered that SST ${ }^{+}$interneuron-derived Collagen XIX, a synaptogenic extracellular matrix protein, is required for the formation of GABAergic, perisomatic synapses by $\mathrm{PV}^{+}$cells. These results, therefore, identify a paracrine mechanism by which early-born SST ${ }^{+}$cells orchestrate inhibitory circuit formation in the developing neocortex.

Key words: collagen; extracellular matrix; inhibitory synapse; neocortex; somatostatin; synaptogenesis

Significance Statement

Inhibitory interneurons in the cerebral cortex represent a heterogenous group of cells that generate the inhibitory neurotransmitter GABA. One such interneuron type is the low-threshold, somatostatin (SST)-expressing cell, which is one of the first types of interneurons to migrate into the cerebral cortex and become incorporated into functional circuits. In addition, to contributing important roles in controlling the flow of information in the adult cerebral cortex, $\mathrm{SST}^{+}$cells play important roles in the development of other neural circuits in the developing brain. Here, we identified an extracellular matrix protein that is released by these early-born $\mathrm{SST}^{+}$neurons to orchestrate inhibitory circuit formation in the developing cerebral cortex.

\section{Introduction}

GABAergic interneurons account for only $\sim 20 \%$ of all cortical neurons, but play essential roles in controlling the spatial and temporal spread of neural activity (Huang et al., 2007; Tremblay et al., 2016). In neocortex, GABAergic interneurons represent a

Received Mar. 19, 2020; revised July 24, 2020; accepted Aug. 18, 2020.

Author contributions: J.S. and M.A.F. designed research; J.S., D.B., S.I., K.S., and J.W. performed research;

J.S., S.I., K.S., J.W., and M.A.F. analyzed data; M.A.F. wrote the paper.

Research in the M.A.F. laboratory is supported by National Institutes of Health (NIH) Grants EY-021222, Al124677, and EY-030568; and by a Brain and Behavior Research Foundation National Alliance for Research in Schizophrenia and Affective Disorders Independent Investigator Award. J.W. was supported by a fellowship provided by a Fralin Biomedical Research Institute at VTC Translational Neurobiology Summer Undergraduate Research Fellowship (neuroSURF) program supported by NIH Grant NS-105141. We thank members of the M. A.F. laboratory for scientific discussions and comments on the manuscript.

The authors declare no competing financial interests.

Correspondence should be addressed to Michael A. Fox at mafox1@vt.edu.

https://doi.org/10.1523/JNEUROSCI.0613-20.2020

Copyright $(2020$ the authors heterogenous group and can be clustered into distinct subtypes based on morphology, physiology, molecular diversification, developmental origin, spatial distribution, and connectivity (Ascoli et al., 2008; Tremblay et al., 2016; Hu et al., 2017; Wamsley and Fishell, 2017; Lim et al., 2018). Genetic, epigenetic, and activitydependent mechanisms underlie the diversification of these interneurons, as well as their incorporation into cortical circuits (De Marco García et al., 2011; Kepecs and Fishell, 2014; Sandberg et al., 2016; Hu et al., 2017; Wamsley and Fishell, 2017; Mayer et al., 2018).

One of the most abundant cortical interneuron subtypes is the fast-spiking cell, which expresses the calcium-binding albumin protein parvalbumin, or Pvalb (abbreviated here as PV). Cortical $\mathrm{PV}^{+}$interneurons are innervated by glutamatergic thalamocortical inputs and generate feedforward, perisomatic inhibitory inputs onto both excitatory pyramidal neurons and other $\mathrm{PV}^{+}$interneurons (Tremblay et al., 2016). These $\mathrm{PV}^{+}$perisomatic synapses play important roles in controlling the flow of 
excitatory activity in neocortex. In fact, disruption of these $\mathrm{PV}^{+}$ circuits leads to seizures and has been associated with a number of neurodevelopmental and psychiatric disorders, including schizophrenia (Benes and Berretta, 2001; Schwaller et al., 2004; Belforte et al., 2010; Gonzalez-Burgos et al., 2010, 2011; Sgadò et al., 2011; Gonzalez-Burgos and Lewis, 2012; Lewis et al., 2012; Wöhr et al., 2015; Ferguson and Gao, 2018).

During embryogenesis, $\mathrm{PV}^{+}$interneurons are generated in the medial ganglionic eminence before undergoing long-range, tangential migration into the developing neocortex (Wonders and Anderson, 2006). Despite being early born, $\mathrm{PV}^{+}$interneuron incorporation into developing cortical circuits is significantly delayed compared with other interneuron subtypes, even those derived from the same germinal zone (Agmon et al., 1996; Huang et al., 1999; Chattopadhyaya et al., 2004; Miyoshi et al., 2010), such as lowthreshold, somatostatin (SST)-expressing interneurons (Wonders and Anderson, 2006; Liguz-Lecznar et al., 2016). Based on their important role in neocortical circuit function and neurodevelopmental and psychiatric disorders, understanding the mechanisms that regulate the incorporation of $\mathrm{PV}^{+}$interneurons into circuits has received considerable attention. Previously, we identified a role for Collagen XIX, a neuron-derived extracellular matrix (ECM) protein associated with familial schizophrenia, in $\mathrm{PV}^{+}$perisomatic synapse assembly (Su et al., 2010, 2016). Specifically, global deletion of Col19a1, the gene encoding Collagen XIX, results in a loss of $\mathrm{PV}^{+}$perisomatic inhibitory synapses, the development of spontaneous seizures, and the acquisition of schizophrenia-related behaviors ( $\mathrm{Su}$ et al., 2016). In vitro analyses further revealed that an endogenously shed C-terminal fragment of Collagen XIX (termed a matricryptin; Ricard-Blum and Salza, 2014) is sufficient to trigger inhibitory synaptogenesis (Su et al., 2016). However, at present, the cellular mechanisms underlying Collagen XIX-triggered perisomatic synapse formation have remained unclear. To address this issue, we generated a novel conditional allele for cell-specific deletion of this nonfibrillar collagen.

Here, we demonstrate that neuron-derived Collagen XIX is indeed necessary for the assembly of perisomatic inhibitory synapses in mouse neocortex. While our previous studies revealed little, if any, expression of Collagen XIX by excitatory neurons or $\mathrm{PV}^{+}$ interneurons (the two main cell types on whose somas $\mathrm{PV}^{+}$perisomatic synapses form), transcriptomic and single-cell analyses suggest that Col19a1 (the gene encoding Collagen XIX) is enriched in $\mathrm{SST}^{+}$interneurons compared with all other cortical cell types (Hrvatin et al., 2018; Lim et al., 2018; Sugino et al., 2006; Krienen et al., 2019). This is particularly interesting since early-born SST ${ }^{+}$ interneurons shape neocortical connectivity and activity during early postnatal development, including shaping the development and maturation of feedforward $\mathrm{PV}^{+}$circuits (Liguz-Lecznar et al., 2016; Tuncdemir et al., 2016; Wang et al., 2019). Based on these data, we sought to test whether $\mathrm{SST}^{+}$interneurons generate Collagen XIX and whether SST ${ }^{+}$interneuron-derived Collagen $\mathrm{XIX}$ is necessary for the formation of $\mathrm{PV}^{+}$perisomatic inhibitory synapses. Our results reveal that multiple $\mathrm{SST}^{+}$interneuron subtypes generate Col19a1 and that conditional loss of SST ${ }^{+}$interneuron-derived Collagen XIX impairs perisomatic inhibitory synapse formation. Together, these data identify a novel paracrine mechanism through which $\mathrm{SST}^{+}$interneurons drive the assembly of feedforward inhibitory circuits in the developing cerebral cortex.

\section{Materials and Methods}

Mouse lines and husbandry. C57BL/6 mice were obtained from Charles River Laboratories. The generation of Collagen XIX-null mice
[Col19a1 ${ }^{-1-}$ (previously referred to as N19)] was previously described (Sumiyoshi et al., 2004; Su et al., 2010). The following primers were used for genotyping Col19a1 ${ }^{-1-}$ mice: Col19al, forward (exon 4): $5^{\prime}$-CTT CGC AAA ACG CAT GCC TCA GA-3'; Col19a1, reverse: 5' -TTG TTC GTT TGT TTG TTT TTA ATC AAT CAA-3'; Lacz, forward: $5^{\prime}$-TTC ACT GGC CGT CGT TTT ACA ACG TCG TGA-3'; and Lacz, reverse: 5'-ATG TGA GCG AGT AAC AAC CCG TCG GAT TCT-3' (Sumiyoshi et al., 2004; Su et al., 2010). PV-Cre, Nes-Cre, Gad2-Cre, and Sst-Cre mice were obtained from The Jackson Laboratory (stock \#008069, \#003771, \#010802, \#013044). Crh-Cre mice (stock \#030850UCD) were obtained from the MMRRC (Mutant Mouse Resource \& Research Centers). The following primers were used for genotyping Cre-expressing mice: Cre, forward: 5' -CGT ACT GAC GGT GGG AGA AT-3'; and Cre, reverse: 5' -TGC ATG ATC TCC GGT ATT GA- $3^{\prime}$. The following two reporter lines were obtained from The Jackson Laboratory: Sun1-sfGFP-Myc (stock \#021039) and Rosa-Stop-tdT (Ai9; stock \#007909). The following primers were used for genotyping GFPand terminal deoxynucleotidyl transferase (tdT)-expressing mice: GFP, forward: 5'-AAG TTC ATC TGC ACC ACC G-3'; GFP, reverse: 5' TCC TTG AAG AAG ATG GTG CG-3'; tdT forward: $5^{\prime}$-ACC TGG TGG AGT TCA AGA CCA TCT-3'; and tdT, reverse: 5' ${ }^{\prime}$ TTG ATG ACG GCC ATG TTG TTG TCC-3' ${ }^{\prime}$. Rosa-Stop-DTA mice were obtained from The Jackson Laboratory (stock \#006331). The following primers were used for genotyping Rosa-Stop-DTA mice: DTA-Common: 5' AAA GTC GCT CTG AGT TGT TAT-3'; DTA-Wt, reverse: 5'-GGA GCG GGA GAA ATG GAT ATG-3'; and DTA-Mut, reverse: 5'-GCG AAG AGT TTG TCC TCA ACC-3'. Mice were housed in a $12 \mathrm{~h}$ dark/ light cycle and had ad libitum access to food and water. All experiments were performed in compliance with National Institutes of Health guidelines and protocols, and were approved by the Virginia Polytechnic Institute and State University Institutional Animal Care and Use Committee.

Generation of Col19a1 ${ }^{\mathrm{f} / \mathrm{fl}}$ mice. A conditional allele of Col19a1 $\left(\right.$ Col19a $\left.{ }^{f l f l}\right)$ mice was generated by Ingenious Targeting Laboratory. Briefly, a $597 \mathrm{bp}$ region of the genome containing exon 4 of Col19al [Fig. 1A (the same region deleted in Col19a1 ${ }^{-1-}$ mice); Sumiyoshi et al., 2004] was targeted. The $5^{\prime}$ LoxP sites were cloned into intron 3 , and a Frt-LoxP-Neo-Frt-LoxP cassette was cloned into intron 4 . The targeting vector was screened, sequenced, and electroporated into iTL HF4 (129/ SvEv $\times$ C57BL/6 FLP) hybrid embryonic stem cells, which were subsequently microinjected into C57BL/6 blastocysts. Resulting chimeras were mated with C57BL/6 WT mice to generate Neo Deleted mice (Fig. $1 A)$. The following primers were used for genotyping Neo Deleted and Col19a $1^{f l f l}$ mice: SC1: $5^{\prime}$-AGT GGG GAT TCA GGG AGG GTA AAG3'; and SDL2: 5' -AAT GCG GGC AGA GTA GCA CTA AGG-3'.

Reagents. Fluorescein RNA Labeling Mix (catalog \#11685619910), digoxigenin (DIG) RNA Labeling Mix (\#11277073910), blocking reagent [in situ hybridization (ISH); catalog \#11096176001], and Yeast RNA (catalog \#10109223001) were from Roche. Proteinase K (catalog \#EO0491), heparin sodium (catalog \#BP2425), and Ambion MAXIscript T7 In Vitro Transcription Kit (catalog \#AM1312) were from Thermo Fisher Scientific. Paraformaldehyde (PFA), EM Grade (catalog \#19202) and Tissue Freezing Medium (catalog \#72592) were from EMS. Prehybridization Solution (catalog \#P1415) was from Sigma. VECTASHIELD mounting medium (catalog \#H-1000) was from Vector Laboratories. The Invitrogen Superscript II Reverse Transcriptase First Strand cDNA Synthesis kit (catalog \#18064014) was from Thermo Fisher Scientific. The Aurum Total RNA Fatty and Fibrous Tissue Kit (catalog \#7326870) was from Bio-Rad. pGEM-T Easy Vector Systems (catalog \#A1360) was from Promega. Tyramide Signal Amplification (TSA) Systems (catalog \#NEL75300 1KT) were from PerkinElmer. The Invitrogen NeuroTrace500/525 (catalog \#N-21 480) was from Thermo Fisher Scientific. All other chemicals and reagents were obtained from Thermo Fisher Scientific or Sigma-Aldrich. All DNA primers were obtained from Integrated DNA Technologies.

Antibodies. The following antibodies were purchased: mouse antiSyt2 [Synaptotagmin 2; znp1; Fox and Sanes, 2007; diluted 1:200 for immunohistochemistry (IHC); Zebrafish International Resource Center]; rabbit anti-vesicular glutamate transporter 1 (VGluT1; diluted 1:500 for IHC; catalog \#135303, Synaptic Systems); rabbit anti-RFT for 
A
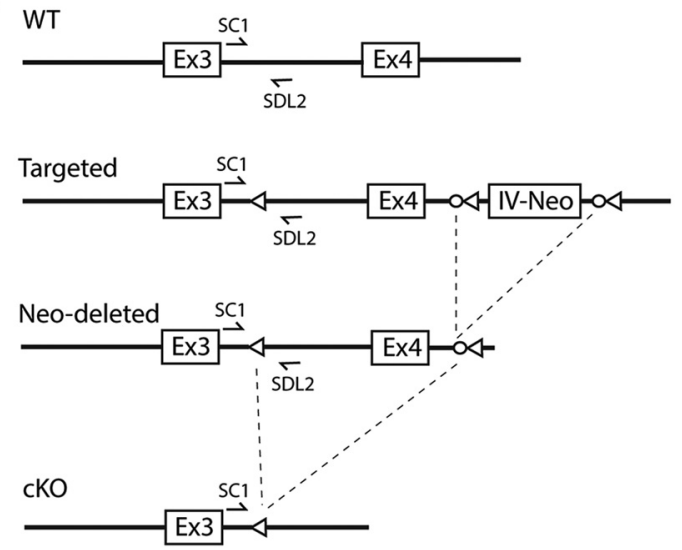

B

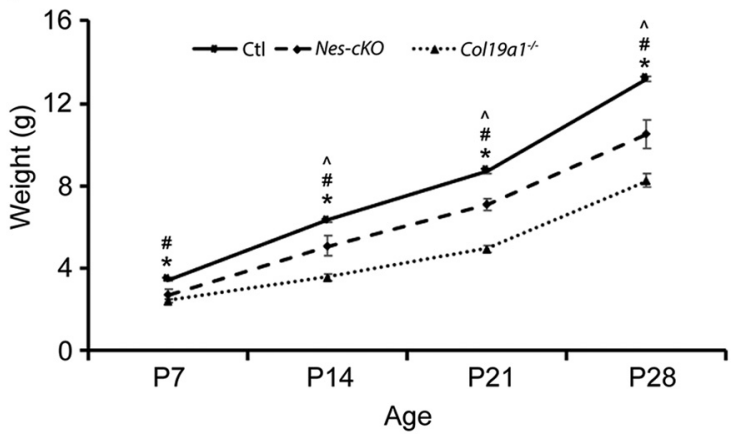

Figure 1. Generation of Col19at ${ }^{f / / f l}$ mice. $A$, Schematic of the strategy to generate $\mathrm{Col}_{19 a 7^{f / f l}}$ mice. LoxP sites (triangles) were inserted to flank exon (Ex) 4 of Col19a1. A neomycin selection cassette (Neo) was inserted after Ex4 and was flanked with flippase (FLP) recombinase target (FRT) sequences (depicted by circles) so that it could be removed in the presence of FLP. cKO alleles were generated by crossing mice carrying Neo-deleted alleles with various (re-driver lines. SC1 and SDL2 represent primer sequences for genotyping. $\boldsymbol{B}$,

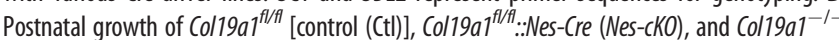
mice. Data points represent the mean \pm SEM. \#Nes-cKO differs from Ctl by $p=0.002$ at P7, $p=0.022$ at $\mathrm{P} 14, p=0.0007$ at $\mathrm{P} 21$, and $p=0.002$ at $\mathrm{P} 28$ by ANOVA; $n=7$ for both genotypes. ${ }^{*} C o / 19 a 1^{-l-}$ differs from $\mathrm{Ctl}$ by $p=0.00,001$ at P7, $p=0.0000008$ at P14, $p=0.000000000002$ at P21, and $p=0.0000001$ at P28 by ANOVA; $n=7$ for $\mathrm{Ctl}$ and $n=13$ for Col19a1 ${ }^{-1-}$. aNes-CKO differs from Col19a1 ${ }^{-1-}$ by $p=0.003$ at P14, $p=0.000003$ at P21, and $p=0.004$ at P28 by ANOVA; $n=7$ for Nes-CKO and $n=13$ for Col19a ${ }^{-1-}$.

tdT (diluted 1:500 for IHC; catalog \#600-401-379, Rockland); Mouse Anti-Parvalbumin (diluted 1:1000 for IHC; catalog \#MAB1572, Chemicon); Invitrogen rabbit anti-GFP (diluted 1:250 for IHC; catalog \#A-11122, Thermo Fisher Scientific); mouse anti-GAD67 (diluted 1:1000 for IHC; catalog \#MAB5406, EMD Millipore); mouse anti-Cre (diluted 1:500 for IHC; catalog \#MAB3120, EMD Millipore); sheep (POD)-conjugated anti-DIG (diluted 1:2000; catalog \#11426346910, Roche); and sheep (POD)-conjugated anti-FL (diluted 1:2000; catalog \#11207733910, Roche).

Tissue preparation and immunohistochemistry. Fluorescent IHC was performed on $20 \mu \mathrm{m}$ cryosectioned PFA-fixed brain tissue (Fox et al., 2007; Su et al., 2010, 2012, 2016). Tissue slides were allowed to air dry for $15 \mathrm{~min}$ before being incubated with blocking buffer $(2.5 \%$ normal goat serum, $2.5 \% \mathrm{BSA}$, and $0.1 \%$ Triton $\mathrm{X}-100$ in PBS) for $30 \mathrm{~min}$. Primary antibodies were diluted in blocking buffer and incubated on tissue sections overnight at $4^{\circ} \mathrm{C}$. On the next day, tissue slides were washed in PBS, and secondary antibodies diluted 1:1000 in blocking buffer were applied to slides for $1 \mathrm{~h}$ at room temperature. After thorough washes in PBS, tissue slides were coverslipped with VECTASHIELD (Vector Laboratories). Images of tissue were acquired on a confocal microscope (LSM 700, Zeiss) equipped with a $20 \times$ air Plan-Apochromat objective [numerical aperture (NA) 0.8 ; Zeiss] and a $40 \times$ oil EC Plan-NeoFluar objective (NA 1.3; Zeiss). When comparing different ages of tissues or between genotypes, images were acquired with identical parameters, and similar gamma adjustments were made to age-matched mutant and control images in Adobe Photoshop or ImageJ. A minimum of three animals (per genotype and per age) were compared in all IHC experiments. Mean fluorescent intensities of IHC images were measured in ImageJ (Singh et al., 2012; Su et al., 2016). For quantification of perisomatic synapses, single optical sections of confocal images were analyzed, and the density of synaptic elements (Syt2 ${ }^{+}$puncta) was quantified per unit length of the cell surface in ImageJ.

Riboprobe making and in situ hybridization. ISH was performed on $20 \mu \mathrm{m}$ sagittal cryosectioned tissues (Su et al., 2010, 2016). Antisense riboprobes were generated from full-length Col19a1 (EMM100297504659), Spon1 (MMM1013-202701079), and Col25a1 (MMM1013202707906) Image Clones (Dharmacon), as described previously (Su et al., 2010, 2016; Monavarfeshani et al., 2017; Carrillo et al., 2018). Antisense riboprobes were generated against a 598 bp fragment of Sst (corresponding to nucleotides 362-960) that was PCR cloned into pGEM Easy T Vector (Promega) with the following primers: $5^{\prime}$-AGC GGC TGA AGG AGA CGC TAC-3'; and 5' -CGC CAT AAT CTC ACC ATA ATT TTA-3'. In brief, riboprobes were synthesized using DIG-labeled UTP (Roche) and the MAXIscript In Vitro Transcription Kit (Ambion). Probes were hydrolyzed to $500 \mathrm{nt}$. Tissue sections were fixed in $4 \%$ PFA for $10 \mathrm{~min}$, washed with DEPC-PBS three times, and incubated in proteinase $\mathrm{K}$ solution $(1 \mu \mathrm{g} / \mathrm{ml}$ proteinase $\mathrm{K}, 50 \mathrm{~mm}$ Tris, $\mathrm{pH}$ 7.5 , and 5 mm EDTA) for $10 \mathrm{~min}$. Subsequently, slides were washed with DEPC-PBS, fixed with $4 \%$ PFA for 5 min, washed with DEPC-PBS, and incubated in acetylation buffer $(1.33 \%$ triethanolamine, $20 \mathrm{~mm} \mathrm{HCl}$, and $0.25 \%$ acetic anhydride) for $10 \mathrm{~min}$. Slides were then permeabilized in $1 \%$ Triton X-100 for $30 \mathrm{~min}$ and washed with DEPC-PBS. Endogenous peroxidase was blocked by incubation in $0.3 \% \mathrm{H}_{2} \mathrm{O}_{2}$ for $30 \mathrm{~min}$. Tissue sections were equilibrated in hybridization buffer $(1 \times$ prehybridization, $0.1 \mathrm{mg} / \mathrm{ml}$ yeast tRNA, $0.05 \mathrm{mg} / \mathrm{ml}$ heparin, and $50 \%$ formamide) for $1 \mathrm{~h}$ and incubated with probes at $65^{\circ} \mathrm{C}$ overnight. After washing in $0.2 \times$ SSC at $65^{\circ} \mathrm{C}$, bound riboprobes were detected by horseradish peroxidase (HRP)-conjugated anti-DIG (diluted 1:2000; Roche) or anti-FL (diluted 1:2000; Roche) antibodies followed by fluorescent staining with TSA Systems (PerkinElmer). After mounting sections in VECTASHIELD, images were obtained on a Zeiss LSM 700 Confocal Microscope equipped with a $20 \times$ air Plan-Apochromat objective (NA 0.8). A minimum of three animals per genotype and age were compared in ISH experiments.

Image quantification. To quantify the number of Col19a1-expressing cells with Sst and Spon1 or Col25a1, we manually counted $>150$ Col19a1 $^{+}$cells and $>250 \mathrm{Sst}^{+}$cells in supragranular and infragranular layers of different cortical regions or different layers/subregions of the hippocampus. Data were collected from three mice per genotype (WT or Sst-Cre:: Rosa-Stop-tdT). These data were used to generate the percentage of Col19a1 cells that express Sst and vice versa. We used similar methods to quantify the percentage of Col19a1 cells that coexpressed SST and Spon1 or SST and Col25a1.

For quantification of perisomatic synapses, single optical sections of confocal images were analyzed, and the density of synaptic elements (Syt2 ${ }^{+}$puncta) was quantified per unit length of the cell surface in ImageJ. Student's $t$ tests were used to determine any significant difference of the mean values between groups.

The intensity of presynaptic terminals in sections of cortex was measured in ImageJ. Three to four animals (eight more sections per animal) were analyzed per genotype, and the mean values were compared between groups. Student's $t$ tests were used to determine any significant difference of the mean values between groups.

Quantitative real-time PCR. RNA was isolated using the Bio-Rad Total RNA Extraction from Fibrous and Fatty Tissue kit (Bio-Rad). cDNAs were generated from $250 \mathrm{ng}$ RNA with the Invitrogen Superscript II Reverse Transcription First Strand cDNA Synthesis Kit (Thermo Fisher Scientific). Quantitative real-time PCR (qRT-PCR) was performed on a Chromo4 Four Color Real-Time PCR system (Bio-Rad) using iTaq SYBRGreen Supermix (Bio-Rad; Su et al., 2016). Col19a1 primers for qRT-PCR were as follows: $5^{\prime}$-ATT GGA CAT AAG GGC GAC AA-3'; and 5'-AGT CTC CTT TGG CTC CTG GT-3'. Gapdh primers 
for qRT-PCR were as follows: 5' -CGT CCC GTA GAC AAA ATG GT3'; and 5'-TTG ATG GCA ACA ATC TCC AC-3'. Spon1 primers for qRT-PCR were as follows: $5^{\prime}$-CGG CCA CAG GAC AGT TAC TC-3'; and 5'-TCA AAG AGA ACC AGG AGG GA-3'. Col25a1 primers for qRT-PCR were as follows: $5^{\prime}$-GAT TCT CCT CTT GG CCT CT- $3^{\prime}$; and $5^{\prime}$-AAA TAA GAA CGG CCA GGG AG-3'. Sst primers for qRT-PCR were as follows: $5^{\prime}$-GAA GGA GAC GCT ACC GAA G-3'; and 5' -AAA GCC AGG ACG ATG CAG-3'. qRT-PCR primers were designed over introns. The following cycling conditions were used with $10 \mathrm{ng}$ RNA: $95^{\circ} \mathrm{C}$ for $30 \mathrm{~s}$, followed by 40 cycles of amplification $\left(95^{\circ} \mathrm{C}\right.$ for $5 \mathrm{~s}, 60^{\circ} \mathrm{C}$ for $30 \mathrm{~s}, 55^{\circ} \mathrm{C}$ for $60 \mathrm{~s}$, read plate) and a melting curve analysis. Relative quantities of RNA were determined using the $\Delta \Delta-\mathrm{Ct}$ method. A minimum of double experiments (each in triplicate) was run for each gene. Each individual run included separate Gapdh control reactions.

Mouse weight measurement. Mice were weighed at postnatal day 7 (P7), P14, P21, and P28. At least 10 mice were weighed per genotype and age. Mean weights were compared between groups, and one-way ANOVAs (using GraphPad Prism 8) were used to determine significant differences between groups.

Nest-building assay. Approximately $1 \mathrm{~h}$ before the dark phase of the light/dark cycle, mice were transferred into clean cages and housed singly for $12 \mathrm{~h}$. One cotton nestlet was added in the same location of each cage. Each cotton nestlet weighed $\sim 2.8 \mathrm{~g}$ at the onset of the experiment. The next morning, we assessed the nests in two ways. First, we visually scored each nest with a rating scale of $1-5(1,>90 \%$ of the cotton nestlet remained intact; $2,50-90 \%$ of the cotton nestlet remained intact; 3, 50$90 \%$ of the nestlet was shredded; $4,>90 \%$ was shredded but the nest was not complete; $5,>90 \%$ was torn and the nest was complete; $\mathrm{Su}$ et al., 2016; Deacon, 2006). Second, we weighed the portions of each nestlet that remained unused (which included any fragments weighing $>0.1 \mathrm{~g}$ ). All mice analyzed were 3-5 months old. The data presented were obtained from 6 Col19al $1^{f l f l}::$ Nes-cre mutants and 8 littermate controls; 9 Col19a1 $1^{f l / f l}:: G a d 2$-cre mutant and 13 littermate controls; and 14 Col19a $1^{f l f l}::$ Sst-cre mutant and 6 littermate controls. Each mouse was assayed once per week, and this was repeated for 3 consecutive weeks. Student's $t$ tests were used to determine significant differences between groups.

Pentylenetetrazol-induced seizures. To assess responses to druginduced seizures, mice were injected with pentylenetetrazol (PTZ; $40 \mu \mathrm{g} /$ $\mathrm{kg}$ in $0.2 \mathrm{ml} \mathrm{PBS}$ ) and then visually monitored for $15 \mathrm{~min}$ as described previously (Brooks et al., 2015; Su et al., 2016). Seizures were scored manually every minute after with the following scoring criteria: 0 , normal activity; 1 , reduced motility and prostate position; 2 , partial clonus; 3 , generalized clonus; 4 , tonic-clonic seizure; and 5 , death. All data were from 9 Col19a1 $1^{\mathrm{fl} / \mathrm{fl}}::$ Nes-cre mutant mice and 10 littermate controls; 15 Col19a $1^{f l / f l}::$ Gad2-cre and 10 littermate controls; and 16 Col19a fl/fl::Sstcre mutant mice and 14 littermate controls. All mice were 3-5 months old. Student's $t$ tests were used to determine significant differences between groups at each time point.

Crawley sociability and social novelty preference assay. The Crawley sociability and social novelty preference assay was performed in a standard three-chamber box (Stoelting), with an open middle chamber that allows free access to each of the flanking chambers, as described previously (Kaidanovich-Beilin et al., 2011; Su et al., 2016). The test mouse was habituated in the middle chamber for $5 \mathrm{~min}$, and a novel conspecific male was placed inside a wire containment cup in one side of the chamber. The duration of contacts between the subject and either the empty housing or the housing containing the novel conspecific was recorded by three video cameras. A single 10 min session was performed for each subject. Social memory was immediately tested by placing a new, novel conspecific male in the empty chamber and leaving the previous (now familiar) conspecific in place. For $10 \mathrm{~min}$, the duration of contacts between the subject and either the novel conspecific or the familiar conspecific was recorded. StreamPix 5 was used to analyze the data. All data were from 16 Coll $a 1^{\mathrm{fl} / \mathrm{fl}}::$ Nes-cre mutant mice and 17 littermate controls; 22 Col19a $1^{f l f l}:: G a d 2$-cre and 17 littermate controls; and 14 Col19a $1^{f l f l}::$ Sst-cre mutant mice and 15 littermate controls. All mice were 3-5 months old. Student's $t$ tests were used to determine significant differences between groups.
Experimental design and statistical analysis. The ages, genotypes, experimental conditions, and number of animals used for each experiment are included both in the Materials and Methods above and in the figure legends. For all experiments, both male and female mice were used. For imaging-based experiments, at least three to four animals were analyzed per genotype and group. For behavioral experiments, the number of animals ranged from 6 to 22, depending on the task. Student's $t$ test or oneway ANOVAs were used to determine any significant difference of the mean values between groups using GraphPad Prism 8. For each experiment, the statistical test used, the number of animals analyzed, and the specific $p$ values are listed in the Results and/or in the figure legends.

\section{Results}

\section{Brain-derived Collagen XIX is necessary for perisomatic} inhibitory synapse formation

Global loss of Col19a1 impairs the formation of $\mathrm{PV}^{+}$inhibitory nerve terminals in the developing cerebral cortex and subiculum (Su et al., 2010, 2016). This could result from the specific loss of Collagen XIX from neurons or, indirectly, from roles of Collagen XIX outside of the brain (Sumiyoshi et al., 1997). To distinguish these possibilities, we generated a conditional allele of Col19a1 $\left(\right.$ Col19a1 $\left.^{f l f l}\right)$ in which LoxP sites flanked exon 4 of Col19a1, the same region deleted in Col19a1 ${ }^{-1-}$ mutants (Fig. 1A; Sumiyoshi et al., 2004). We initially crossed this conditional allele with NesCre, a driver line in which Cre Recombinase (Cre) is generated by neuronal and glial progenitors early in the developing brain (Tronche et al., 1999). Col19a1 ${ }^{f l f f l}:$ Nes-Cre $e^{+}$mutant mice are born in expected Mendelian ratios, are viable and fertile, and are indistinguishable from littermate controls as adults. However, Col19a $1^{f l f l}:: N e s-\mathrm{Cre}^{+}$mutants are significantly smaller than littermate controls during the first 4 weeks of postnatal development, although they are significantly larger than Col19a1 ${ }^{-1-}$ mutants at these ages (Fig. $1 B$ ).

To assess the formation of inhibitory GABAergic synapses in Col19a1 $1^{f l f l}:: N e s-C r e^{+}$mutants, GABAergic nerve terminals were labeled with antibodies directed against Syt2, a synaptic vesicleassociated protein whose expression in neocortex is largely restricted to $\mathrm{PV}^{+}$GABAergic interneurons (Sommeijer and Levelt, 2012; Su et al., 2016). In layer V of both visual and prefrontal cortex, we detected significantly fewer Syt $2^{+}$nerve terminals in Col19al $^{f l f l}:: N e s-\mathrm{Cre}^{+}$mutants compared with controls (Fig. 2A$F)$. While brain-derived Collagen XIX appears to be necessary for GABAergic synapse formation, we detected no significant alteration in the density, distribution, or morphology of excitatory nerve terminals (e.g., those labeled with antibodies against VGluT1 in these regions of Col19a ${ }^{f l f l}:: N e s-\mathrm{Cre}^{+}$mice (Fig. 2AF).

Since $\mathrm{PV}^{+}$interneurons generate perisomatic inhibitory synapses onto pyramidal neurons and other $\mathrm{PV}^{+}$interneurons (Pfeffer et al., 2013; Pi et al., 2013), we next examined the distribution of these nerve terminals in the developing neocortex of $\mathrm{Col19a1}^{f l / f l}$;Nes-Cre ${ }^{+}$mutants. Neuronal somas in layer V of neocortex were labeled with either NeuroTrace or antibodies against $\mathrm{PV}$, and perisomatic inhibitory nerve terminals were labeled with antibodies against Syt2. Significantly fewer Syt $2^{+}$perisomatic synapses were observed contacting the somas of both types of neurons in the absence of brain-derived Collagen XIX (Fig. $2 G-L)$.

Expression of Col19a1 is restricted to subsets of GABAergic interneurons in neocortex (Su et al., 2016), so we repeated these analyses in Col19a1 ${ }^{f l f l}:: G a d 2-\mathrm{Cre}^{+}$mutants. Cre is generated in the majority of neocortical GABAergic cells in Gad2-Cre ${ }^{+}$ mice, including in Col19a1-expressing cells (data not shown). 

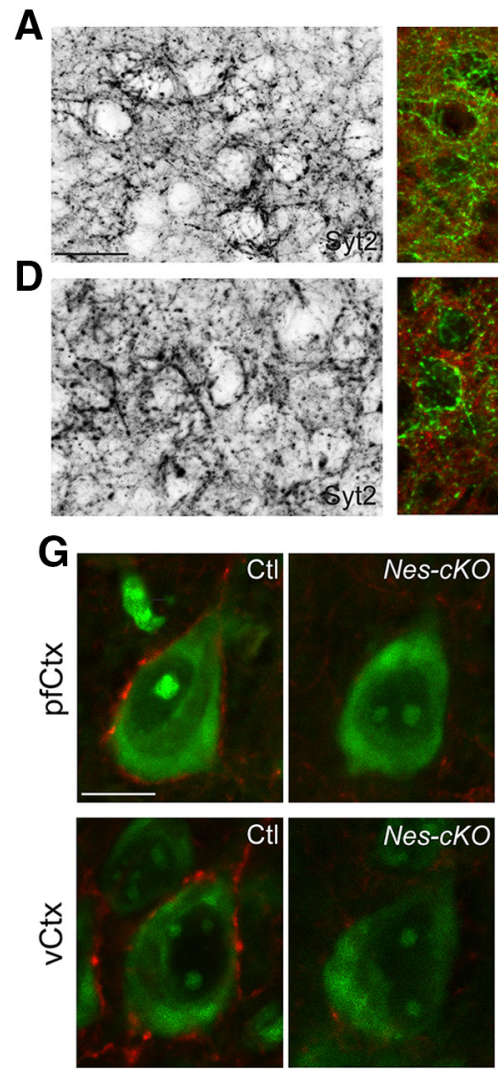

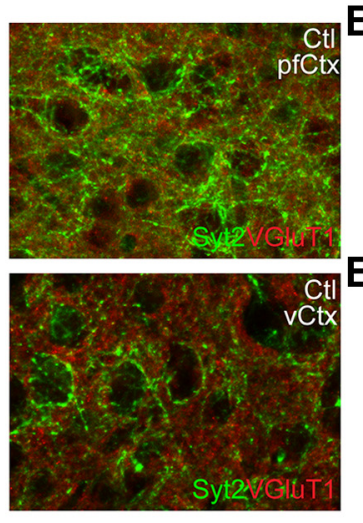

H

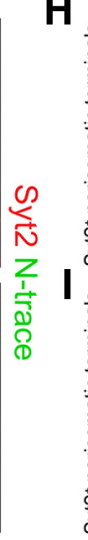

B

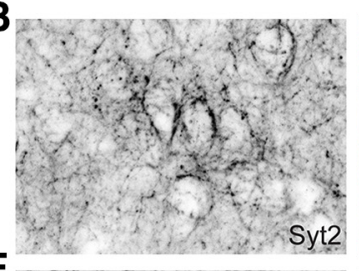

E
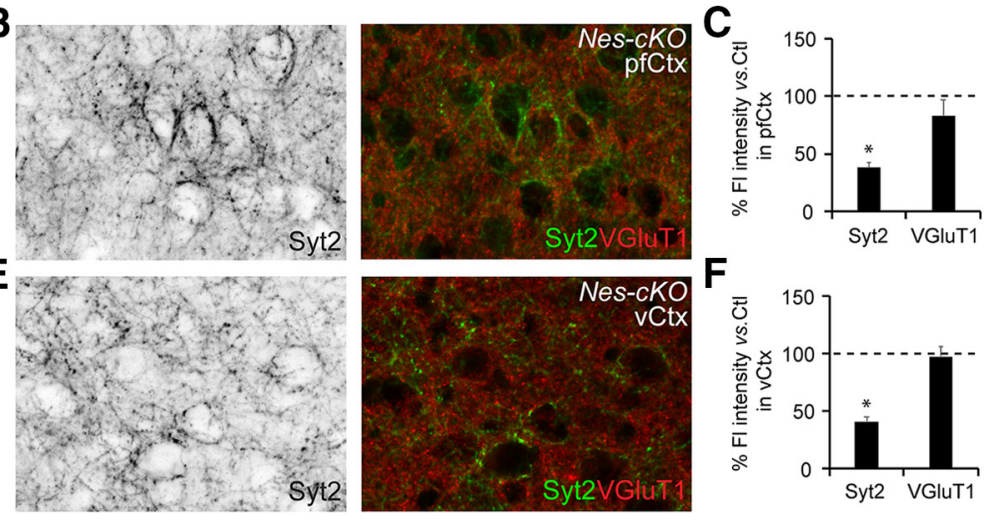

$F$
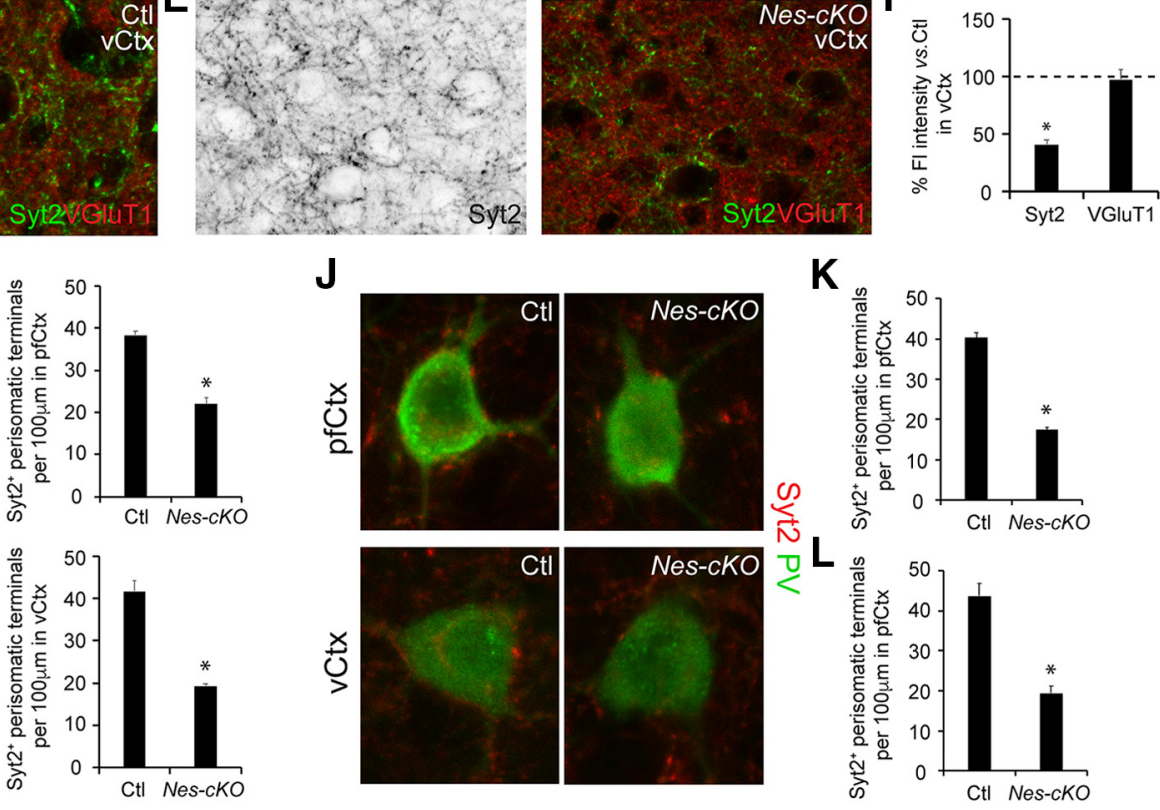

J
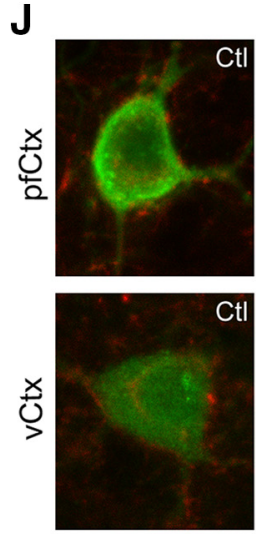
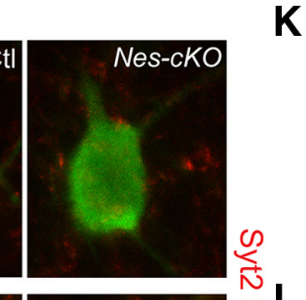

K

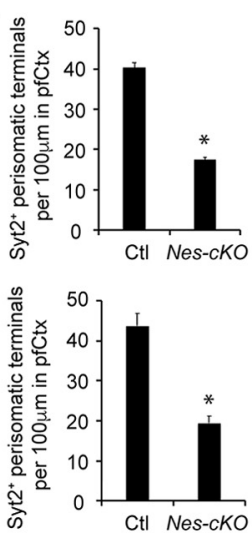

Figure 2. Loss of brain-derived Collagen XIX leads to impaired inhibitory perisomatic synapse formation. $\boldsymbol{A}, \boldsymbol{B}$, Immunostaining for Syt2 and VGluT1 in layer V of prefrontal cortex (pfCtx) in P14 Col19a $7^{f / / f}:$ :Nes-Cre (Nes-cKO) mutants and littermate controls (Ctls). C, Mean fluorescent intensity of Syt2 and VGluT1 in layer V of pfCtx in P14 Nes-CKO and Ctl mice. Dashed line represents Ctl values. Data represent the mean $\pm S D ; n=3$. *Differs from Ctl by $p=0.00006$ by Student's $t$ test. $\boldsymbol{D}, \boldsymbol{E}$, Immunostaining for Syt2 and VGluT1 in layer V of visual cortex (vCtx) in P14 Nes$c K 0$ and $\mathrm{Ctl}$ mice. $\boldsymbol{F}$, Mean fluorescent intensity of Syt2 and VGluT1 in layer V of vCtx in P14 Nes-cKO and Ctl mice. Dashed line represents Ctl values. Data represent the mean \pm SD; $n=3$. *Differs from Ctl by $p=0.0005$ by Student's $t$ test. $G$, Immunostained Syt2 ${ }^{+}$perisomatic synapses were analyzed on NeuroTrace (N-trace)-labeled neurons in single optical sections from layer $\mathrm{V}$ of pfCtx and vCtx in P14 Nes-CKO and Ctl mice. $\boldsymbol{H}, \boldsymbol{I}$, Reduced numbers of Syt2 ${ }^{+}$perisomatic synapses (per unit length of cell soma) on N-trace-labeled neurons in pfCtx and vCtx of P14 NescKO mutants. Data represent the mean \pm SD; $n=3$. * Differs from Ctl by $p=0.0002$ (pfCtx), $p=0.0003$ (vCtx) by Student's $t$ test. J, Immunostained Syt2 ${ }^{+}$perisomatic synapses were analyzed on PV-immunolabeled neurons in single optical sections from layer V of pfCtx and vCtx in P14 Nes-cKO and Ctl mice. $\boldsymbol{K}, \boldsymbol{L}$, Reduced numbers of Syt2 ${ }^{+}$perisomatic synapses (per unit length of cell soma) on $\mathrm{PV}^{+}$neurons in pfCtx and vCtx of P14 Nes-CKO mutants. Data represent means $\pm \mathrm{SD} ; n=3$. *Differs from Ctl by $p=0.00,001$ (pfCtx), $p=0.0008$ (vCtx) by Student's $t$ test. Scale bars: (in $A) A, B, D, E, 20 \mu \mathrm{m}$; (in $G) G, J, 10 \mu \mathrm{m}$.

Col19a1 $1^{f l f l}:: G a d 2-C r e^{+}$mutant mice are born in expected Mendelian ratios, are viable and fertile, and are indistinguishable from littermate controls as adults. Loss of Collagen XIX from Gad2-expressing cells in P14 Col19a1 $1^{f l f l}:: G a d 2-C r e^{+}$ mutants resulted in reduced Syt $2^{+}$perisomatic nerve terminals, as described above in Col19a ${ }^{f l / f l}:: N e s-C r e^{+}$mutants (Fig. 3). Together, studies in both Col19a1 $1^{f l f l}:: \mathrm{Nes}_{-} \mathrm{Cre}^{+}$and Col19a1 $1^{f l f l}:: G a d 2-C r e^{+}$demonstrate that interneuron-derived Collagen XIX is necessary for the formation of $\mathrm{PV}^{+}$inhibitory circuits in the developing neocortex.

Loss of brain-derived collagen XIX results in phenotypes associated with dysfunctional inhibitory neocortical circuits The loss of $\mathrm{PV}^{+}$perisomatic synapses in cerebral cortex (because of the loss of Collagen XIX or a number of other genetic and environmental factors) leads to spontaneous seizures, enhanced susceptibility to drug-induced seizures, and the acquisition of a number of behaviors associated with neurodevelopmental disorders, such as schizophrenia (Schwaller et al., 2004; KrookMagnuson et al., 2013; Rossignol et al., 2013; Wöhr et al., 2015; Su et al., 2016). To assess seizure susceptibility in Col19a1 $^{f l f f}::$ $\mathrm{Nes}^{-\mathrm{Cre}^{+}}$and Col19a1 $1^{f l f l}:: \mathrm{Gad} 2-\mathrm{Cre}^{+}$mutants (and controls), we administered low doses of the GABA antagonist PTZ and monitored seizure activity for $16 \mathrm{~min}$. At low doses $(40 \mathrm{mg} /$ $\mathrm{kg}$ ), PTZ induced mild motor seizures in control mice (Fig. $4 A, B)$. Identical doses of PTZ resulted in significantly enhanced seizure susceptibility in both Col19a1 ${ }^{f l / f l}:: N e s-C r e^{+}$ and Col19af ${ }^{f l f f}:: G a d 2-C r e^{+}$mutants, in terms of both increased seizure scores (i.e., seizure severity) and faster onset of motor seizures (Fig. 4A,B).

Next, to assess whether either mutant exhibits altered behavior associated with schizophrenia, we assessed mutant performance in a nest-building assay (which models the negative symptoms associated with schizophrenia; Belforte et al., 2010; Albrecht and Stork, 2012; Pedersen et al., 2014) and in a preference for social novelty task (which models social affiliation and memory; Moy et al., 2004; Fig. 4C,H,I). Previously, we showed that Col19a1 $1^{-/-}$mice exhibit impaired performance in both of these tasks (Su et al., 2016). Here, our results indicate impaired nest-building activity in both Col19a1 ${ }^{f l f l}:: N e s-C r e^{+}$and Col19a1 $1^{f l f l}:: G a d 2-C r e^{+}$mutants (Fig. 4D-G). Moreover, while control mice spend significantly more time investigating novel conspecific mice (compared with the time they spend investigating familiar mice), both conditional mutants spend equal time investigating novel and familiar conspecifics (Fig. $4 J-M$ ). Thus, loss of either brain- or interneuron-derived Collagen XIX leads to the acquisition of abnormal behaviors. 

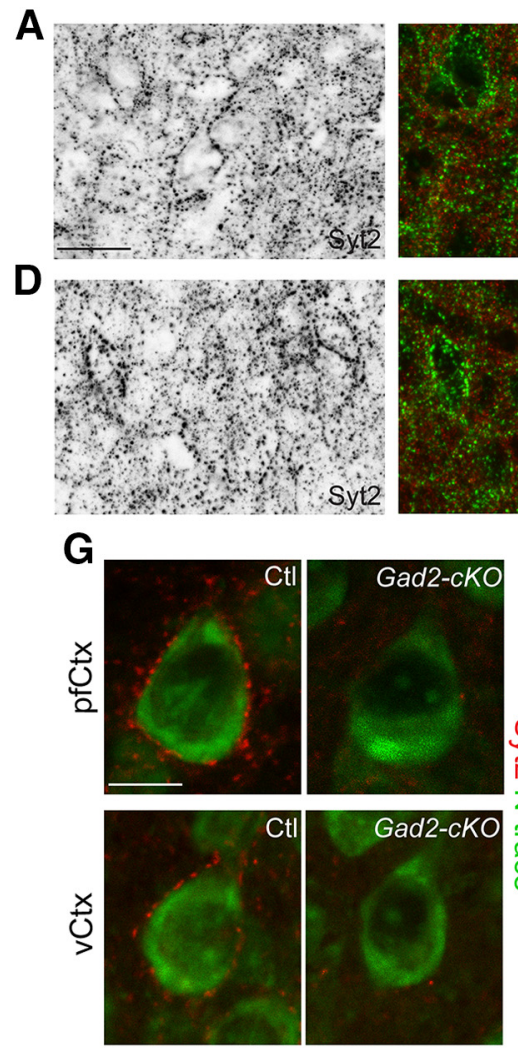
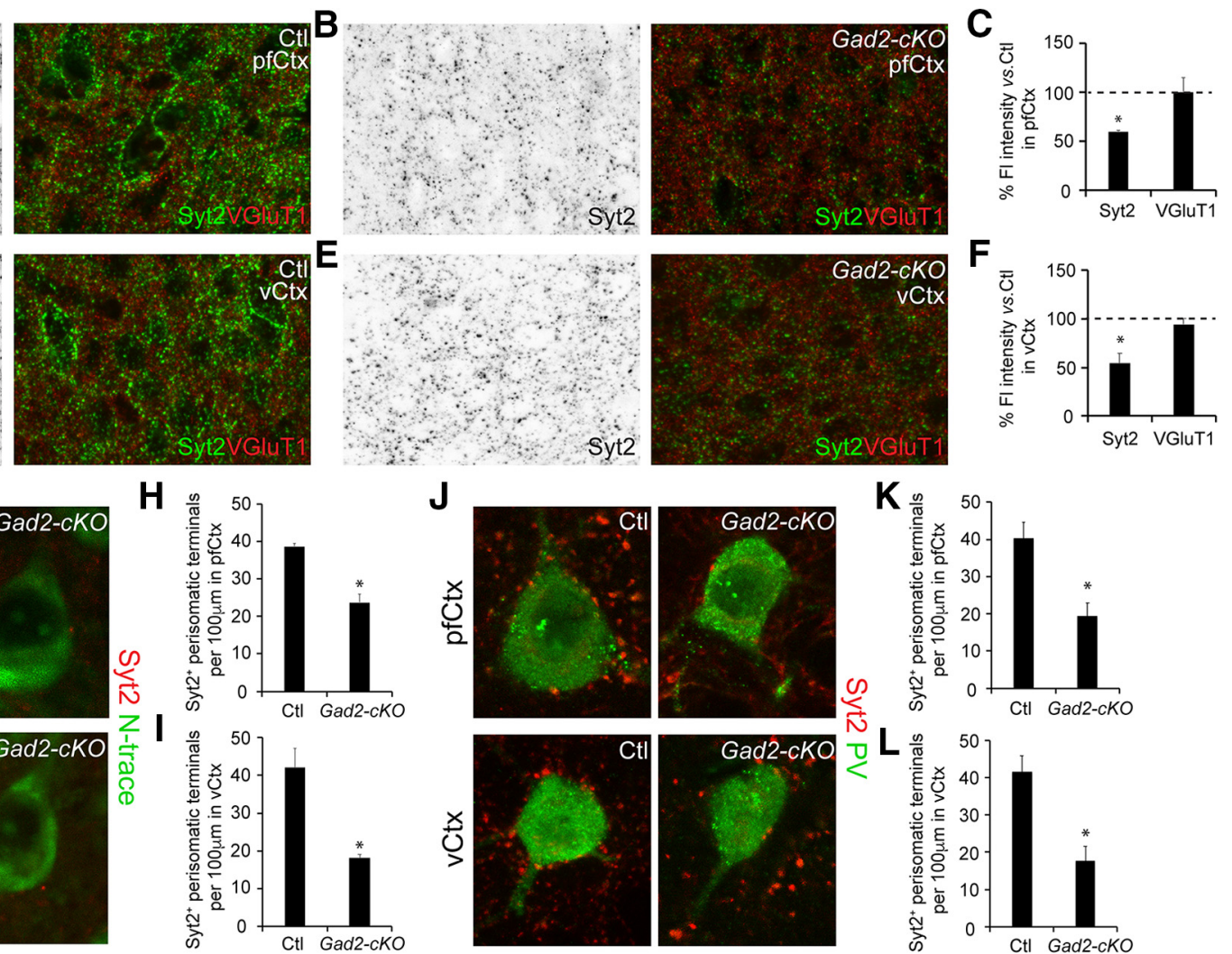

$F$
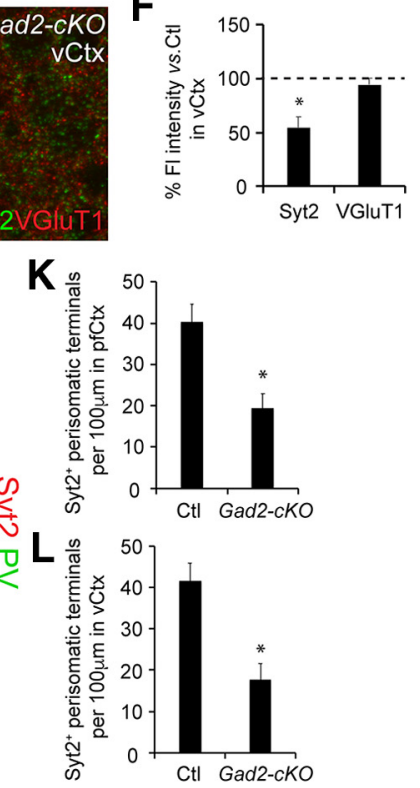

Figure 3. Loss of GABAergic neuron-derived Collagen XIX leads to impaired inhibitory perisomatic synapse formation. $A, B$, Immunostaining for Syt2 and VGluT1 in layer V of prefrontal cortex (pfCtx) in P14 Col19a 1//if::Gad2-Cre (Gad2-cKO) mutants and littermate controls (Ctls). C, Mean fluorescent intensity of Syt2 and VGluT1 in layer V of pfCtx in P14 Gad2-cKO and Ctl mice. Dashed line represents Ctl values. Data represent the mean $\pm S D ; n=3$. *Differs from Ctl by $p=0.001$ by Student's $t$ test. $D, E$, Immunostaining for Syt2 and VGluT1 in layer V of visual cortex (vCtx) in P14 Gad2-cKO and Ctl mice. $\boldsymbol{F}$, Mean fluorescent intensity of Syt2 and VGluT1 in layer V of vCtx in P14 Gad2-cKO and Ctl mice. Dashed line represents Ctl values. Data represent the mean $\pm S D ; n=3$. *Differs from Ctl by $p=0.003$ by Student's $t$ test. $\mathbf{G}$, Immunostained Syt2 ${ }^{+}$perisomatic synapses were analyzed on NeuroTrace (N-trace)-labeled neurons in single optical sections from layer $\mathrm{V}$ of pfCtx and vCtx in P14 Gad2-cKO and $\mathrm{Ctl}$ mice. $\boldsymbol{H}, \mathbf{I}$, Reduced numbers of Syt2 ${ }^{+}$perisomatic synapses (per unit length of cell soma) on $\mathrm{N}$-trace-labeled neurons in pfCtx and vCtx of P14 Gad2-cKO mutants. Data represent the mean \pm SD; $n=3$. *Differs from Ctl by $p=0.0009$ (pfCtx), $p=0.003$ (vCtx) by Student's $t$ test. J, Immunostained Syt2 ${ }^{+}$perisomatic synapses were analyzed on PV-immunolabeled neurons in single optical sections from layer V of pfCtx and vCtx in P14 Gad2-cKO and Ctl mice. $\boldsymbol{K}, \boldsymbol{L}$, Reduced numbers of Syt2 ${ }^{+}$perisomatic synapses (per unit length of cell soma) on PV ${ }^{+}$neurons in pfCtx and vCtx of P14 Gad2-cKO mutants. Data represent the mean $\pm \mathrm{SD} ; n=3$. ${ }^{*}$ Differs from Ctl by $p=0.006$ (pfCtx), $p=0.004$ (vCtx) by Student's $t$ test. Scale bars: (in $\boldsymbol{A}) \boldsymbol{A}, \boldsymbol{B}, \boldsymbol{D}, \boldsymbol{E}, 20 \mu \mathrm{m}$; (in $\boldsymbol{G}) \mathbf{G}, \boldsymbol{J}, 10 \mu \mathrm{m}$.

\section{$\mathrm{SST}^{+}$interneurons in cerebral cortex generate Col19a1}

While Col19a1 mRNA is generated by cortical interneurons, little, if any, is generated by $\mathrm{PV}^{+}$interneurons (Su et al., 2016). Unbiased transcriptomic studies recently have suggested that it is instead generated by SST ${ }^{+}$cells in neocortex. To test whether telencephalic $\mathrm{SST}^{+}$interneurons do in fact generate Col19a1, we generated riboprobes against both Col19a1 and Sst mRNAs and performed in situ hybridization (Fig. 5A,B). We also performed in situ hybridization with Col19al riboprobes on brain slices from Sst-Cre::Rosa-Stop-tdT transgenic mice, in which SST ${ }^{+}$ interneurons are fluorescently labeled with tdT (Fig. 5C,D). In both sets of experiments, we observed the expression of Col19a1 mRNA by SST ${ }^{+}$interneurons in both supragranular and infragranular layers of the developing neocortex (Fig. 5A-F). These results suggest that the majority of brain-derived Collagen XIX is produced by $\mathrm{SST}^{+}$interneurons. To test this hypothesis, we assessed Col19a1 mRNA expression in Sst-Cre::Rosa-Stop-DTA mice, in which diphtheria toxin A (DTA) is selectively expressed in $\mathrm{SST}^{+}$neurons leading to the ablation of these cells (Ivanova et al., 2005; Tuncdemir et al., 2016). As expected, qRT-PCR revealed a significant reduction in Sst mRNA in Sst-Cre::RosaStop-DTA mutants (Fig. 5G). Thus, $\mathrm{SST}^{+}$interneurons appear to be a predominant source of Col19a1 mRNA in the developing mouse neocortex.
Clustering of cell types by single-cell transcriptomic analysis has revealed the presence of at least two (if not more) transcriptionally distinct subsets of GABAergic $\mathrm{SST}^{+}$interneurons in mouse cortex (Hrvatin et al., 2018; Mayer et al., 2018). In these studies, Spon1 (which encodes F-Spondin) and Col25a1 (which encodes Collagen XXV) are generated by distinct subtypes of $\mathrm{SST}^{+}$interneurons (with Spon1 mRNA being enriched in type I $\mathrm{SST}^{+}$interneurons and Col25a1 mRNA being enriched in type II SST $^{+}$interneurons; Hrvatin et al., 2018; Mayer et al., 2018). To test whether Col19a1 is generated by a select subtype of SST ${ }^{+}$ interneurons, we generated riboprobes against Spon1 and Col25a1. In situ hybridization in Sst-Cre::Rosa-Stop-tdT transgenic mice revealed that Spon1 and Col25a1 are generated in distinct cortical layers: Spon $1^{+} / S s t^{+}$cells are distributed in infragranular cortical layers, and Col25a1 ${ }^{+} / S s t^{+}$cells are distributed in supragranular cortical layers (Fig. 5I-L). This suggests laminar specificity of type I and type II $\mathrm{SST}^{+}$neurons. Interestingly, while in situ hybridization revealed that both Spon1 and Col25a1 are generated in $\mathrm{SST}^{+}$interneurons (labeled in Sst-Cre:: Rosa-Stop-tdT transgenic mice; Fig. 5I-L), we found that Spon1 mRNA, but not Col25a1 mRNA, is significantly reduced in the neocortex of Sst-Cre; Rosa-Stop-DTA mutant mice (Fig. $5 H$ ). As an aside, this result, coupled with the persistence of some Sst mRNA in these mutants (Fig. $5 G$ ), suggests that perhaps only a subset of Sst ${ }^{+}$neurons is ablated in Sst-Cre; Rosa- 

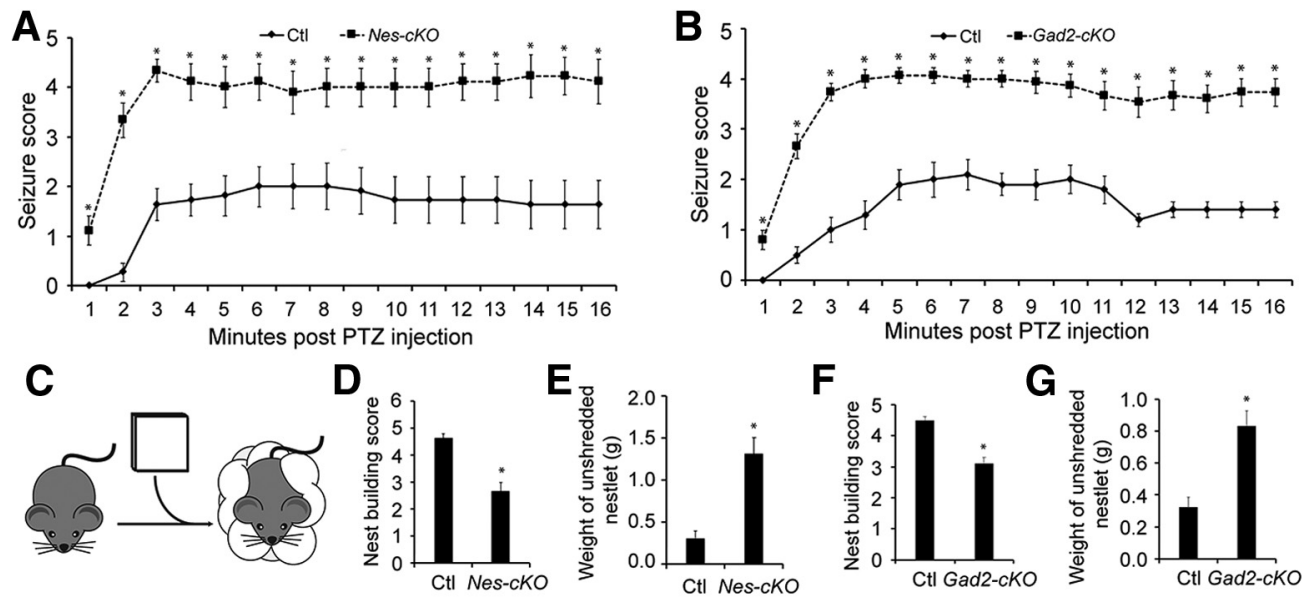

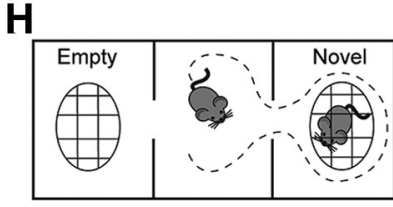

I

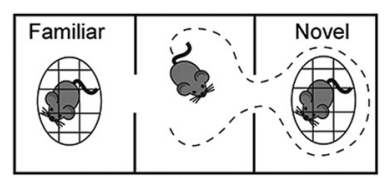

$\mathbf{J}$

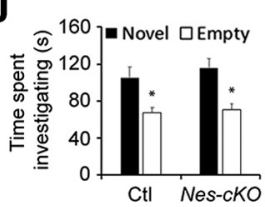

K

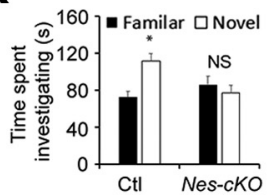

$\mathbf{L}$

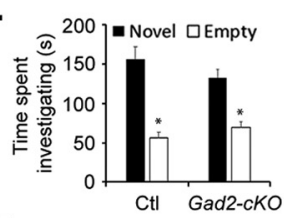

M

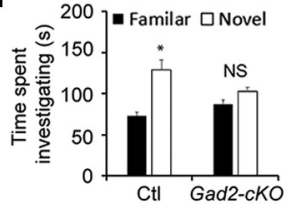

Figure 4. Mice lacking brain- or GABAeregic neuron-derived Collagen XIX are more susceptible to drug-induced seizures and exhibit altered behavior. $A, B$, Seizure scores for Ctl, Nes-CKO, and Gad2-CKO mutants were recorded for $16 \mathrm{~min}$ after the administration of PTZ. Data represent the mean \pm SEM; in $\boldsymbol{A}, n=11 \mathrm{Ctl}$ and $n=9$ Nes-cKO; in $\boldsymbol{B}, n=10 \mathrm{Ctl}$ and $n=15 \mathrm{Gad2}$-cKO. *Differs from Ctt by $p<0.01$ by Student's $t$ test. C, Schematic representation of nest-building behavior. $\boldsymbol{D}-\boldsymbol{G}$, Nests were scored manually after $12 \mathrm{~h}(\boldsymbol{D}, \boldsymbol{F})$ or by weighing unused nestlets after $12 \mathrm{~h}(\boldsymbol{E}, \boldsymbol{G})$. Data represent the mean \pm SEM; $p=0.0009$ for weight and $p=0.0005$ for score by Student's $t$ test; in $\boldsymbol{D}$ and $\boldsymbol{E}, n=8 \mathrm{Ctl}$ and $n=6$ Nes-cKO; in $\boldsymbol{F}$ and $\boldsymbol{G}, n=13 \mathrm{Ctl}$ and $n=9$ Gad2-cKO. *Differs from Ctl by $p=0.0002$ for weight and $p=0.00002$ for score by Student's $t$ test. $\boldsymbol{H}, \boldsymbol{I}$, Schematic of sociability $(\boldsymbol{H})$ and social memory $(\boldsymbol{I})$ assays. J-M, Nes-cKO, Gad2-cKO, and $C t l$ mice spent significantly more time investigating novel conspecifics versus empty chambers $(\boldsymbol{J}, \boldsymbol{L})$; while $C t$ mice also spent significantly more time investigating novel conspecifics versus familiar conspecifics $(\boldsymbol{K}, \boldsymbol{M})$, the same was not true for Nes-cKO and Gad2-cKO mutants. Data represent the mean \pm SEM; in $\boldsymbol{J}$ and $\boldsymbol{K}, n=17 \mathrm{Ctl}$ and $n=16 \mathrm{Nes-CKO}$; in $\boldsymbol{L}$ and $\boldsymbol{M}, n=17 \mathrm{Ctl}$

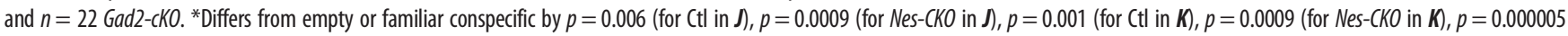
(for $\mathrm{Ctl}$ in $\boldsymbol{L}$ ), $p=0.00,002$ (for Nes-CKO in $\boldsymbol{L}$ ), $p=0.0002$ (for $\mathrm{Ctl}$ in $\boldsymbol{M}$ ) by Student's $t$ test. NS, Not significantly different.

Stop-DTA mice. Finally, combining in situ hybridization for Col19a1 and either Spon1 and Col25a1 in Sst-Cre::Rosa-Stop-tdT transgenic mice revealed that both type I and type II SST ${ }^{+}$interneurons generate Col19a1 in neocortex (Fig. 5I-P).

\section{SST-derived Collagen XIX is necessary for perisomatic inhibitory synapse formation}

Next, to specifically test whether SST-derived Collagen XIX is necessary for the formation of $\mathrm{PV}^{+}$perisomatic synapses, we generated Col19a1 ${ }^{f l f f l}::$ Sst-Cre $e^{+}$mutants. These mutants are born in expected Mendelian ratios, are viable and fertile, and exhibit significant reduction in Col19a1 mRNA expression in neocortex $\left(0.59 \pm 0.04\right.$-fold Col19a1 mRNA expression in Col19a1 ${ }^{\text {flffl }}::$ Sst$\mathrm{Cre}^{+}$neocortex vs control; $p=0.003$ by Student's $t$ test). Col19a1 $^{f l f l}::$ Sst-Cre ${ }^{+}$mutants exhibit similar structural and behavioral phenotypes described above for Col19a1 ${ }^{f l f f l}:: N e s-C r e^{+}$ and Col19a1 ${ }^{f l / f l}:: G a d 2-C r e^{+}$mutants (Figs. 2-4) and previously for Col19a1 ${ }^{-1-}$ mutants (Su et al., 2016; Figs. 6-8). This includes a reduced density of both Syt $2^{+}$and GAD $67^{+}$inhibitory nerve terminals in layer $\mathrm{V}$ of the developing neocortex (Figs. 6A-F, 7) and a significant reduction in Syt $2^{+}$perisomatic synapses onto neocortical pyramidal neurons and $\mathrm{PV}^{+}$interneurons (Fig. 6G$L)$. As was the case for all other mutant alleles of Col19a1 examined to date, no differences in $\mathrm{VGluT}^{+}$excitatory nerve terminals were observed in Col19al ${ }^{f l f l}:: S s t-C r e^{+}$mutants compared with littermate controls (Fig. $6 A-F$ ). Defects in $\mathrm{PV}^{+} /$Syt2 ${ }^{+}$ perisomatic synapse assembly in the absence of SST-derived Collagen XIX do not merely reflect a delay in neocortical development since similar reductions in these inhibitory synapses were observed in adult Col19a1 ${ }^{f l / f l}:: S s t-C r e^{+}$mutants (Fig. 8A-I). Moreover, these adult mutants exhibited significantly elevated susceptibility to PTZ-induced seizures (Fig. 8R) and impaired performance in nest-building and social preference tasks (Fig. $8 S-V)$. Importantly, all of these changes in $\mathrm{PV}^{+} / \mathrm{Syt}^{+}$perisomatic synapses and altered behaviors do not arise from reduced numbers of $\mathrm{PV}^{+}$or $\mathrm{SST}^{+}$interneurons in the absence of SSTderived Collagen XIX (Fig. 8J-Q). Together, all of these results suggest that SST-derived Collagen XIX acts in a paracrine fashion for the assembly of $\mathrm{PV}^{+}$perisomatic synapses.

Finally, while SST-derived Collagen XIX is required for the proper assembly of perisomatic inhibitory synapses, these analyses did not rule out roles for other specific types of cortical interneurons in this process. To assess roles of other defined populations of neocortical interneurons, we crossed Col19a ${ }^{f l f l}$ mice to other Cre driver lines that exhibit subtype-specific expression in neocortical interneurons. Although few $\mathrm{PV}^{+}$interneurons generate Collagen XIX (Su et al., 2010, 2016), we assessed the role of limited PV-derived Collagen XIX by crossing 

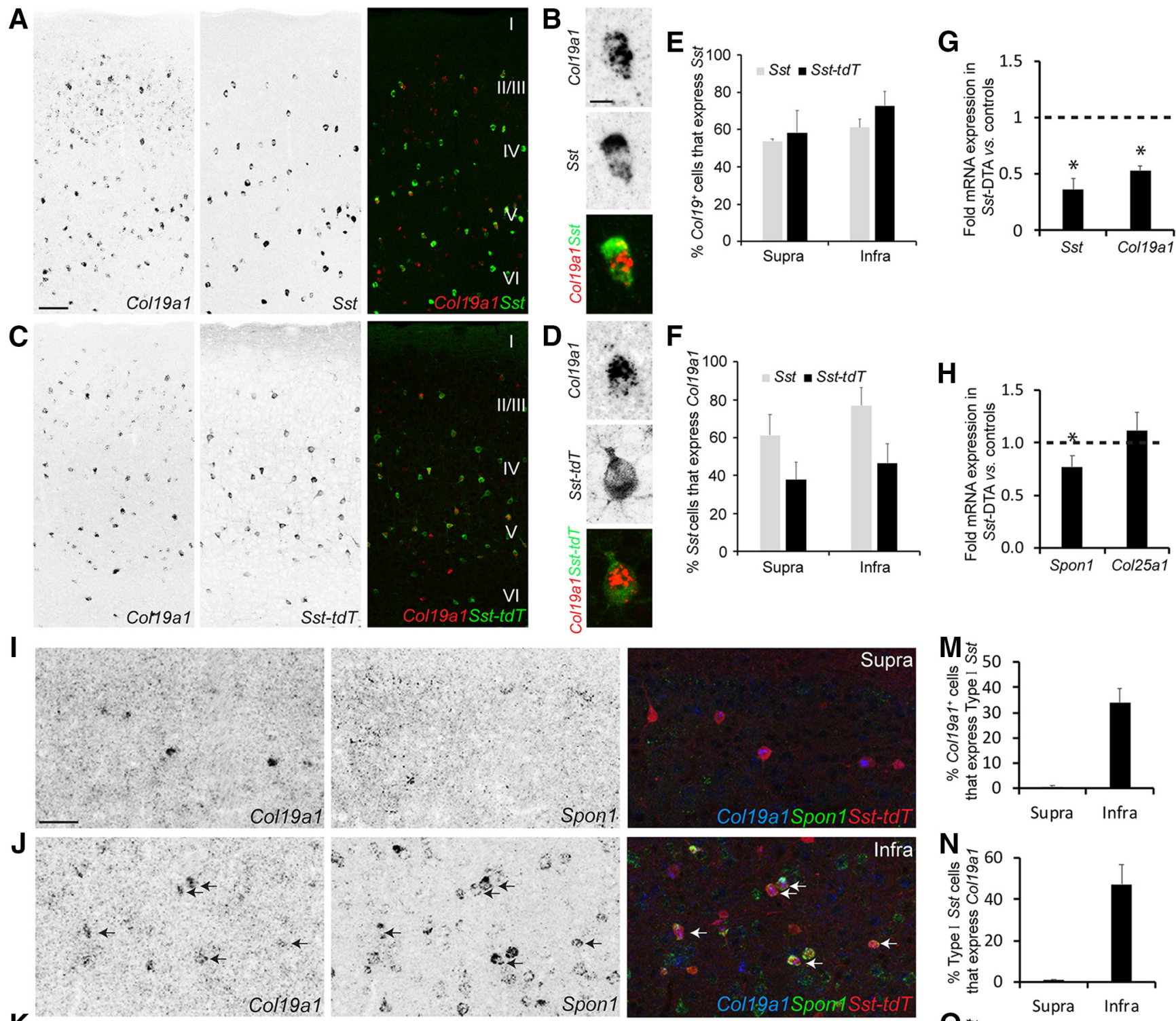

K

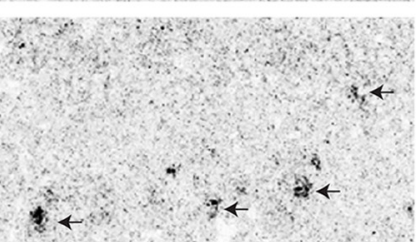

L
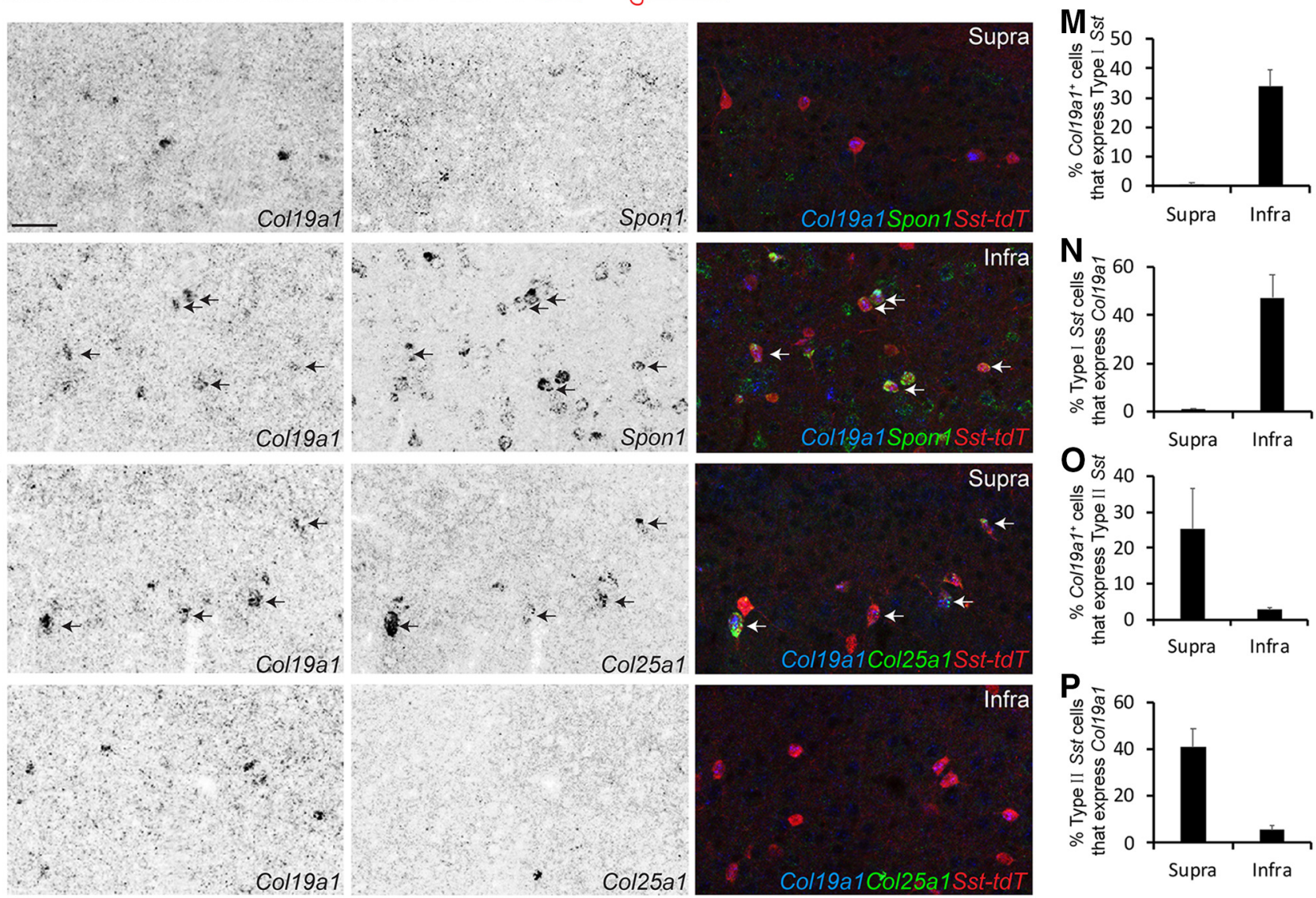

Figure 5. Collagen XIX is generated by neocortical SST ${ }^{+}$neurons. $\boldsymbol{A - D}$, In situ hybridization for Col19a1 mRNA in SST ${ }^{+}$neurons in P14 neocortex. SST ${ }^{+}$neurons labeled by in situ hybridization $(\boldsymbol{A}, \boldsymbol{B})$ or through genetic labeling $(\boldsymbol{C}, \boldsymbol{D})$ in Sst-Cre::Rosa-Stop-tdT mice (Sst-tdT) mice. Cortical layers are labeled in $\boldsymbol{A}$ and $\boldsymbol{C}$. High-magnification images of $\mathbf{C o l 1 9 a 1}$ mRNA in SST ${ }^{+}$neurons are shown in $\boldsymbol{B}$ and $\boldsymbol{D}$. $\boldsymbol{E}$, Quantification of the percentage of Col19a ${ }^{+}$cells expressing Sst mRNA (in wild-type mice) or tdT (in Sst-tdT mice) in supragranular (Supra) or infragranular (Infra) layers of neocortex. Bars depict the mean \pm SD. F, Quantification of the percentage of SST cells (identified by Sst mRNA or tdT expression in Sst-tdT mice) that express Col19a1 mRNA in neocortex. Bars depict the mean \pm SD. G, H, qRT-PCR analysis of Sst, Col19a1, Col25a1, and Spon1 mRNA expression in neocortex of P7 control (dashed line) or Sst-Cre::Rosa-Stop-DTA mice. Bars depict the mean \pm SD. ${ }^{*} p=0.001$ for Sst $(\boldsymbol{G}), p=0.0003$ for Col19a1 (G), $p=0.04$ for Spon1 (H) compared with control by Student's $t$ test $(n=3)$. $\boldsymbol{I}-\boldsymbol{L}$, In situ hybridization for Col19a1 and either Col25a1 or Spon1 in the supragranular (Supra) or infragranular (Infra) layers of neocortex in P22 Sst-Cre::Rosa-Stop-tdT (Sst-tdT) mice. M-P, Quantitation of the coexpression of Col19a1 in Spon $1^{+} / \mathrm{Sst}^{+}$(type I) cells and Col25a1 ${ }^{+} / \mathrm{Sst}^{+}$(type II) cells in the supragranular (Supra) or infragranular (Infra) layers of neocortex. Bars depict the mean \pm SD. Scale bars: (in $\boldsymbol{A}$ ) $\boldsymbol{A}$, C, $100 \mu \mathrm{m}$; (in $\boldsymbol{B}) \boldsymbol{B}, \boldsymbol{D}, 10 \mu \mathrm{m}$; (in I) $\boldsymbol{I}-\boldsymbol{L}, 50 \mu \mathrm{m}$. 


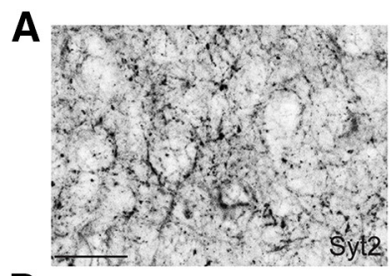

D
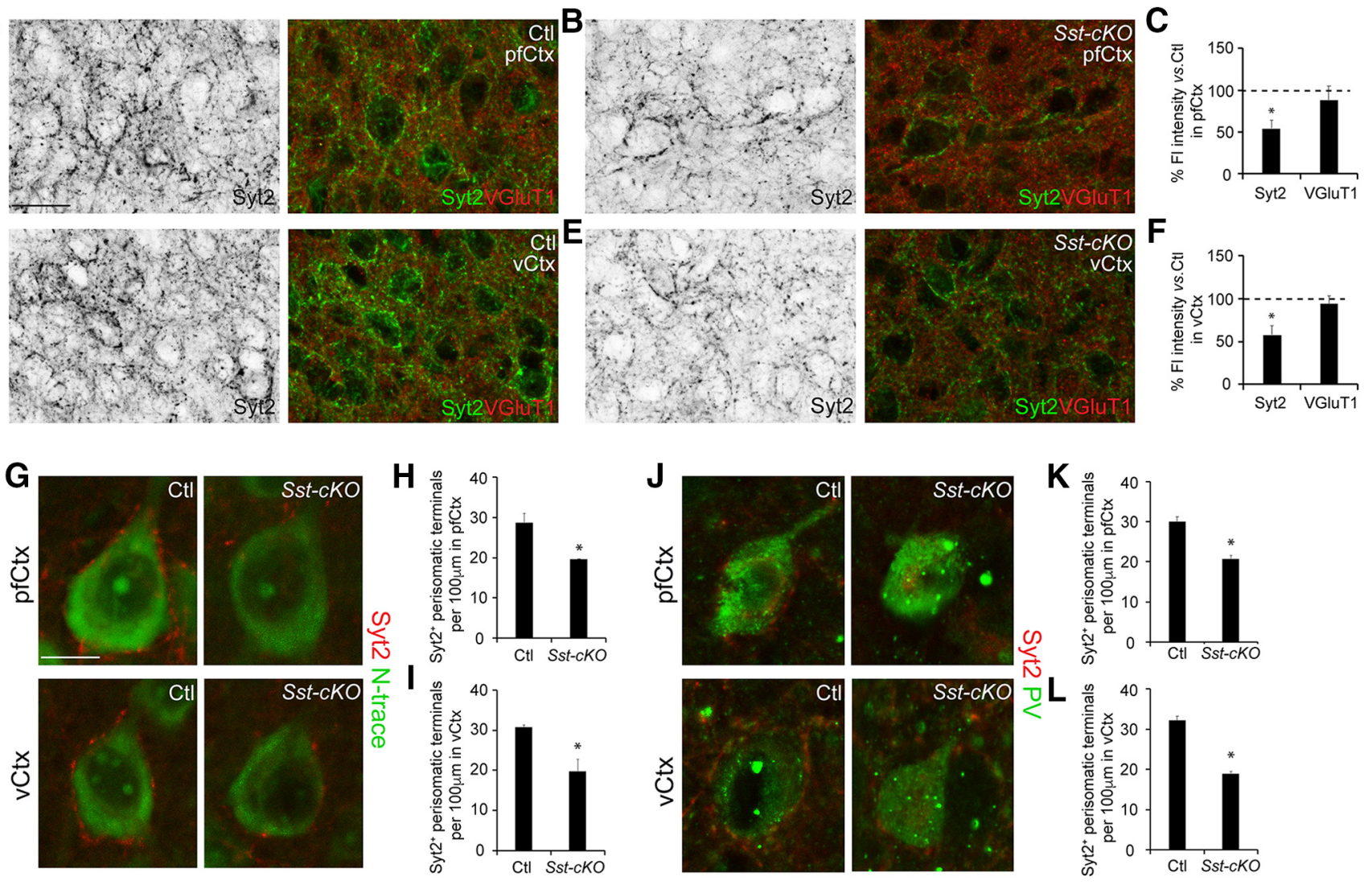

Figure 6. Loss of SST ${ }^{+}$neuron-derived Collagen XIX leads to impaired inhibitory perisomatic synapse formation. $\boldsymbol{A}, \boldsymbol{B}$, Immunostaining for Syt2 and VGluT1 in layer V of prefrontal cortex (pfCtx) in P14 Col19a1 ${ }^{f / f l}$ ::Sst-Cre (Sst-cKO) mutants and littermate controls (Ctls). C, Mean fluorescent intensity of Syt2 and VGluT1 in layer V of pfCtx in P14 Sst-cKO and Ctl. Dashed line represents Ctl values. Data represent the mean \pm SD; $n=3$. *Differs from Ctl by $p=0.006$ by Student's $t$ test. $\boldsymbol{D}, \boldsymbol{E}$, Immunostaining for Syt2 and VGluT1 in layer V of visual cortex (vCtx) in P14 Sst-cKO and CtI mice. $\boldsymbol{F}$, Mean fluorescent intensity of Syt2 and VGluT1 in layer V of vCtx in P14 Sst-cKO and Ctl mice. Dashed line represents Ctl values. Data represent the mean \pm SD; $n=3$. *Differs from Ctl by $p=0.007$ by Student's $t$ test. $\mathbf{G}$, Immunostained Syt $2^{+}$perisomatic synapses were analyzed on NeuroTrace (N-trace)-labeled neurons in single optical sections from layer $V$ of pfCtx and vCtx in P14 Sst-cKO and Ctl. $\boldsymbol{H}, \boldsymbol{I}$, Reduced numbers of Syt2 ${ }^{+}$perisomatic synapses (per unit length of cell soma) on N-trace-labeled neurons in pfCtx and vCtx of P14 Sst-cKO mutants. Data represent the mean \pm SD; $n=3$. *Differs from Ctl by $p=0.005$ (pfCtx), $p=0.007$ (vCtx) by Student's $t$ test. J, Immunostained Syt2 ${ }^{+}$perisomatic synapses were analyzed on PV-immunolabeled neurons in single optical sections from layer V of pfCtx and vCtx in P14 Sst-cKO and Ctl mice. $\boldsymbol{K}$, $\boldsymbol{L}$, Reduced numbers of Syt2 ${ }^{+}$perisomatic synapses (per unit length of cell soma) on PV ${ }^{+}$neurons in pfCtx $(\boldsymbol{K})$ and vCtx $(\boldsymbol{L})$ of P14 Sst-CKO mutants. Data represent the mean \pm SD; $n=3$. *Differs from Ctl by $p=0.001$ (pfCtx), $p=0.00,007$ (vCtx) by Student's $t$ test. Scale bars: (in $\boldsymbol{A}) \boldsymbol{A}, \boldsymbol{B}, \boldsymbol{D}, \boldsymbol{E}, 20 \mu \mathrm{m}$; (in $\boldsymbol{G}) \mathbf{G}, \boldsymbol{J}, 10 \mu \mathrm{m}$.

Col19a ${ }^{f l f l}$ mice to $P V$-Cre mice. To inhibit the production of Collagen XIX from other subtypes of interneurons, we crossed our floxed allele to Crh-Cre mice. Cre is generated in a large subset of $\mathrm{SST}^{-} / \mathrm{PV}^{-}$interneurons in Crh-Cre mice (Taniguchi et al., 2011). The developmental assembly of inhibitory nerve terminals in these mutants was examined using approaches identical to those described above for all other conditional mutants. We observed no alterations in Syt $2^{+}$inhibitory nerve terminals in for Col19a1 $1^{f l f l}:: P V-C r e^{+}$and Col19al ${ }^{f l f l}:: C r h-C r e^{+}$mutants (Fig. 9), suggesting that Collagen XIX is not required from these classes of interneurons for the assembly of perisomatic synapses.

\section{Discussion}

Early-born, cortical SST ${ }^{+}$interneurons orchestrate cortical circuit development

Despite sharing a common embryonic origin with $\mathrm{PV}^{+}$interneurons (Xu et al., 2004), $\mathrm{SST}^{+}$interneurons represent the earliest interneuron population to tangentially migrate into infragranular cortical layers and integrate into circuits (Miyoshi and Fishell, 2011; Tuncdemir et al., 2016; Lim et al., 2018). These early-born $\mathrm{SST}^{+}$interneurons not only help to shape patterns of synchronous activity in the developing cortex, but they also help to shape the development of cortical connectivity (Bonifazi et al., 2009; Picardo et al., 2011; Tuncdemir et al., 2016; Wang et al., 2019). While genetic ablation of early-born SST ${ }^{+}$interneurons has demonstrated critical roles for these cells in orchestrating the formation and maturation of GABAergic circuits in the infragranular layers of neocortex (Tuncdemir et al., 2016; Wang et al., 2019), the mechanism underlying the paracrine action of these interneurons has remained unclear. One possibility is that the release of SST (which itself is a neuromodulator) or GABA from these early-born interneurons may have trophic, tropic, or synaptogenic effects on developing GABAergic circuits. Both SST and GABA have well established roles in neural development (Gonzalez et al., 1992; Ferriero et al., 1994; Owens and Kriegstein, 2002; Represa and Ben-Ari, 2005; Chen and Kriegstein, 2015; Liguz-Lecznar et al., 2016). Alternatively, the loss of SST ${ }^{+}$interneurons (which shape early patterns of activity in the developing cortex) may result in altered spontaneous network synchronization that impacts GABAergic circuit development (Bonifazi et al., 2009; Picardo et al., 2011). Precise patterns of activity, including GABAergic activity, during early development have well established roles in shaping neural circuit assembly and refinement (Katz and Shatz, 1996; Mohajerani et al., 2007; Huang, 2009; Griguoli and Cherubini, 2017). Interestingly, 
blocking vesicular release of $\mathrm{SST}^{+}$interneurons early in development appears to have little effect on the development and maturation of infragranular GABAergic circuits (including GABAergic perisomatic synapses), suggesting that altered activity or the release of SST or GABA alone may not underlie the orchestration of cortical circuit development by early-born $\mathrm{SST}^{+}$ interneurons (Tuncdemir et al., 2016; Wang et al., 2019). Data presented here support a third option for how these earlyborn interneurons influence GABAergic development-they generate and release synaptogenic cues that drive the assembly of GABAergic synapses in a paracrine fashion. Specifically, our data show that $\mathrm{SST}^{+}$interneurons generate Collagen XIX, a synaptogenic extracellular matrix protein capable of promoting GABAergic synapse formation ( $\mathrm{Su}$ et al., 2016). Conditional
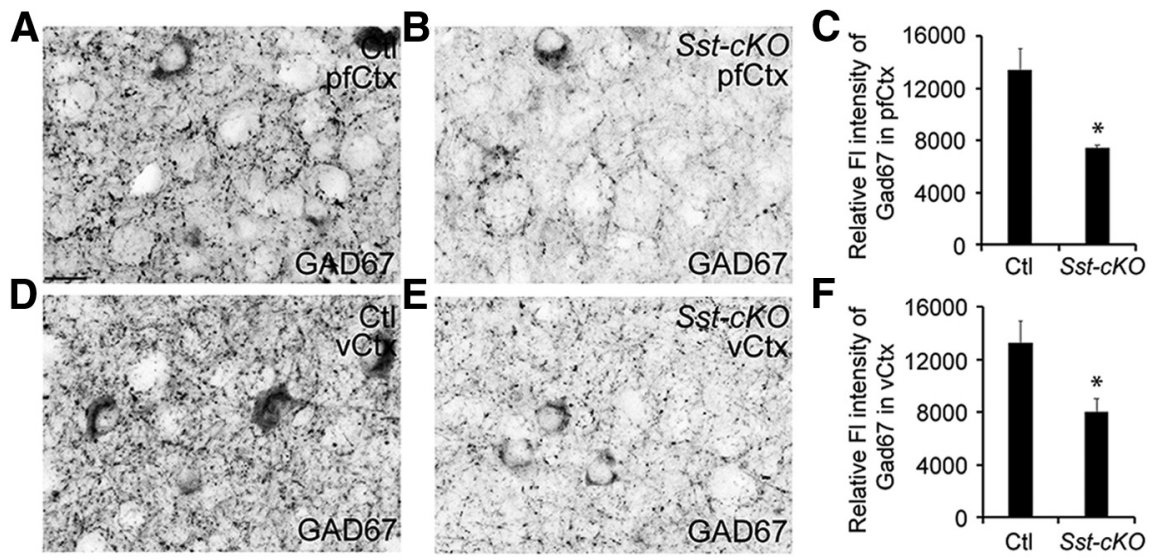

Figure 7. Loss of SST ${ }^{+}$neuron-derived Collagen XIX leads to impaired GAD67 ${ }^{+}$inhibitory nerve terminal formation in neocortex. $\boldsymbol{A}, \boldsymbol{B}$, Immunostaining for GAD67 in layer V of prefrontal cortex (pfCtx) in P14 Col19a fl/fl.:Sst-Cre (Sst-cKO) mutants and littermate controls (Ct|s). C, Mean fluorescent intensity of GAD67 in layer V of pfCtx in P14 Sst-cKO and Ctl mice. Data represent the mean $\pm \mathrm{SD} ; n=3$. *Differs from $\mathrm{Ctl}$ by $p=0.007$ by Student's $t$ test. $\boldsymbol{D}, \boldsymbol{E}$, Immunostaining for GAD67 in layer $\mathrm{V}$ of visual cortex (vCtx) in P14 Sst-cKO and Ctl. $\boldsymbol{F}$, Mean fluorescent intensity of GAD67 in layer V of vCtx in P14 Sst-cKO and $\mathrm{Ctl}$ mice. Data represent the mean $\pm \mathrm{SD} ; n=3$. ${ }^{*}$ Differs from Ctl by $p=0.02$ by Student's $t$ test. Scale bar, $20 \mu \mathrm{m}$. deletion of this unconventional collagen from $\mathrm{SST}^{+}$interneurons (but not from $\mathrm{PV}^{+}$cells) is sufficient to impair the assembly of perisomatic, GABAergic synapses in the infragranular layers of neocortex. Not only does the loss of SST-derived Collagen XIX impair GABAergic synapse development, it increases seizure susceptibility and results in the acquisition of schizophrenia-related behaviors-phenotypes that are all associated with the loss or dysfunction of perisomatic, GABAergic synapses (Schwaller et al., 2004; Gonzalez-Burgos et al., 2011; Lewis et al., 2011; Paz and Huguenard, 2015). Thus, our data reveal a novel role for SST ${ }^{+}$ interneurons in the production of paracrine factors that drive GABAergic synapse formation in the developing cortex.

While it remains unclear why early-born $\mathrm{SST}^{+}$interneurons assume the role of master coordinator of GABAergic circuit formation in the developing cortex, it appears to be a role conserved by early-born interneurons in other brain regions. For example, SST-expressing "hub" neurons orchestrate of circuit development in the developing hippocampus (Picardo et al., 2011; Villette et al., 2016). While there appear to be significant differences between these $\mathrm{SST}^{+}$hippocampal hub neurons and neocortical SST ${ }^{+}$interneurons (Tuncdemir et al., 2016; Wang et al., 2019), SST neurons in both regions produce Collagen XIX during GABAergic circuit formation (Su et al., 2010, 2016). Collagen XIX, however, appears dispensable for GABAergic circuit formation in stratum pyramidalis of CA1 and CA3, and the loss of Collagen XIX impairs perisomatic GABAergic synapse formation in subiculum (Su et al., 2010). Thus, the role of SST-derived Collagen XIX in triggering GABAergic synapse formation is not a cortex-specific phenomenon. It is noteworthy though that Collagen XIX is generated in only a few brain regions (Su et al., 2010 , 2016) making it unlikely to contribute to GABAergic circuit formation in most subcortical regions containing $\mathrm{SST}^{+}$ interneurons.

Paracrine roles for synaptogenic cues in the developing brain The coordinated transformation of presynaptic and postsynaptic elements into functioning synapses has long been interpreted to suggest a role for the precise exchange of developmentally relevant synaptogenic cues from each synaptic partner. Such signals would not only induce presynaptic and postsynaptic differentiation, but they would also direct the precise alignment of neurotransmitter release sites (i.e., active zones) with neurotransmitter receptor clusters on the postsynaptic membrane (Fox and Umemori, 2006; Biederer et al., 2017). Studies over the past 2 decades have identified a number of cell adhesion molecules that localize to presynaptic or postsynaptic membranes, bind trans-synaptically to adhere these closely apposed synaptic membranes, and induce the assembly of machinery for neurotransmitter release and reception. An incomplete list of such synaptic adhesion molecules at central synapses includes neurexins, neuroligins, leucine-rich repeat transmembrane proteins, synaptic cell adhesion molecules, cadherins, EphBs and ephrins, integrins, and Ig superfamily members (Craig et al., 2006; Shen and Scheiffele, 2010; Missler et al., 2012; Jang et al., 2017). As synaptic organizing factors were first identified, it became evident that not all of these cues were embedded in presynaptic or postsynaptic membranes, as neuron-derived secreted cues were discovered that regulate synaptogenesis (including morphogens, growth factors, neurotrophins, and extracellular matrix proteins; Hall et al., 2000; Umemori et al., 2004; Matsuda et al., 2010; Terauchi et al., 2010; Uemura et al., 2010; Kalinovsky et al., 2011; Ito-Ishida et al., 2012; Su et al., 2012; Ferrer-Ferrer and Dityatev, 2018). Moreover, extracellular proteases in or near the synaptic cleft are capable of cleaving the extracellular domains of synaptic adhesion molecules, liberating soluble protein fragments capable of influencing synaptogenesis (Suzuki et al., 2012; Toth et al., 2013). The realization that secreted cues or soluble, shed ectodomains within the extracellular space of the developing brain could impart precise and specific information for inducing synaptogenesis opened the possibility that these synaptogenic cues could be derived from sources other than the synaptic partners and could therefore act in a paracrine fashion (Ferrer-Ferrer and Dityatev, 2018).

To date, glial-derived factors are the best example of synaptogenic cues that act in paracrine fashion (Eroglu and Barres, 2010; Allen and Eroglu, 2017). Astrocytes extend processes to contact presynaptic and postsynaptic elements in the brain (Bushong et al., 2002) and, thus, occupy prime real estate to deliver developmentally relevant cues to influence presynaptic or postsynaptic development, maturation, and function. Many astrocyte-derived synaptogenic cues are ECM proteins, such as thrombospondins, hevin, glypicans, and chondroitin sulfate 

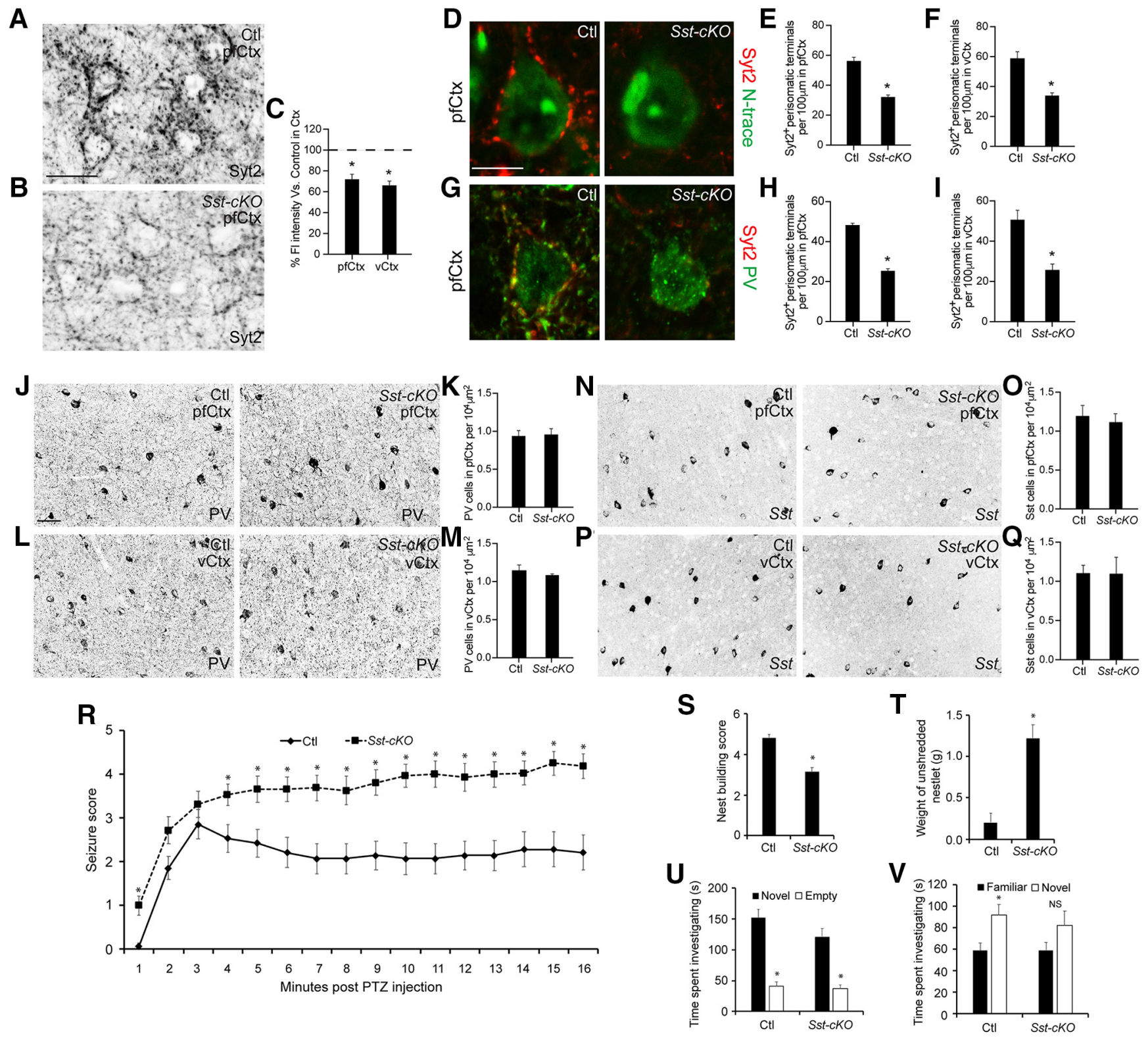

Figure 8. Loss of $\mathrm{SST}^{+}$neuron-derived Collagen XIX leads to reduced perisomatic synapse number in adult mice and impaired behaviors. $\boldsymbol{A}, \boldsymbol{B}$, Immunostaining for Syt2 in layer $\mathrm{V}$ of prefron-

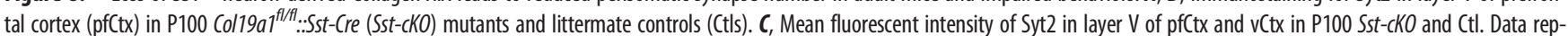
resent the mean $\pm \mathrm{SD} ; n=3$. ${ }^{*}$ Differs from $\mathrm{Ct}$ by $p=0.04(\mathrm{pfCtx})$ and $p=0.0008(\mathrm{vCtx})$ by Student's $t$ test. $\boldsymbol{D}$, Immunostained Syt2 ${ }^{+}$perisomatic synapses were analyzed on NeuroTrace (Ntrace)-labeled neurons in single optical sections from layer V of pfCtx in P100 Sst-cKO and Ctl mice. $\boldsymbol{E}, \boldsymbol{F}$, Reduced numbers of Syt2 ${ }^{+}$perisomatic synapses (per unit length of cell soma) on $\mathrm{N}$ trace-labeled neurons in pfCtx and vCtx of P100 Sst-cKO mutants. Data represent the mean \pm SD; $n=3$. *Differs from Ctl by $p=0.0001$ (pfCtx) $p=0.0008$ (vCtx) by Student's $t$ test. $\boldsymbol{G}$, Immunostained Syt2 ${ }^{+}$perisomatic synapses were analyzed on PV-immunolabeled neurons in single optical sections from layer V of pfCtx in P100 Sst-cKO and Ctl mice. $\boldsymbol{H}, \mathbf{I}$, Reduced numbers of Syt2 ${ }^{+}$perisomatic synapses (per unit length of cell soma) on $\mathrm{PV}^{+}$neurons in pfCtx and $\mathrm{vCtx}$ of P100 Sst-cKO mutants. Data represent the mean $\pm S D ; n=3$. ${ }^{*}$ Differs from Ctl by $p=0.000008$ (pfCtx), $p=0.001$ (vCtx) by Student's $t$ test. $J, L, I H C$ for PV ${ }^{+}$cells in vCtx and pfCtx of P100 Sst-cKO and Ctl mice. $\boldsymbol{K}, \boldsymbol{M}$, Quantification of the density of PV ${ }^{+}$cells in vCtx and pfCtx of P100 Sst-CKO and Ctl mice. Data represent the mean \pm SD; $n=3$. N, $\boldsymbol{P}$, ISH for Sst ${ }^{+}$cells in vCtx and pfCtx of P100 Sst-cKO and Ctl mice. O, $\mathbf{Q}$, Quantification of the density of Sst ${ }^{+}$ cells in vCtx and pfCtx of P100 Sst-cKO and Ctl mice. Data represent the mean $\pm S D ; n=3$. $\boldsymbol{R}$, Seizure scores for Ctl and Sst-cKO mutants were recorded for 15 min after the administration of PTZ. Data represent the mean \pm SEM; $n=14 \mathrm{Ctl}$ and $n=16 \mathrm{Sst-CKO}$. *Differs from Ctl by $p<0.05$ by Student's $t$ test. S, $T$, Nest-building assays. Nests were scored manually after $12 \mathrm{~h}$ or by weighing unused nestlets after $12 \mathrm{~h}$. Data represent the mean $\pm \mathrm{SEM} ; n=6 \mathrm{Ctl}$ and $n=14 \mathrm{Sst}-\mathrm{CKO}$. *Differs from Ctl by $p=0.0003$ for score, $p=0.002$ for weight by Student's $t$ test. $\boldsymbol{U}, \boldsymbol{V}$, Sociability $(\boldsymbol{U})$ and social memory assays $(\boldsymbol{V})$. Sst-CKO and $\mathrm{Ctl}$ spent significantly more time investigating novel conspecifics versus empty chambers (U). While $(\mathrm{tl}$ mice also spent significantly more time investigating novel conspecifics versus familiar conspecifics, the same was not true for Sst-cKO mutants. Data represent the mean \pm SEM; $n=15$ Ctl and 14 Sst-cKO. *Differs from empty or familiar conspecific by $p=0.0000001$ (Ctl in $\boldsymbol{U}$ ), $p=0.00,001$ (Sst-cKO in $\boldsymbol{U}$ ), and $p=0.01,268$ (Ctl in $\boldsymbol{V}$ ) by Student's $\boldsymbol{t}$ test. NS, Not significantly different. Scale bars: (in $\boldsymbol{A}$ ) $\boldsymbol{A}, \boldsymbol{B}$, $20 \mu \mathrm{m}$; (in D) $\boldsymbol{D}, \boldsymbol{E}, 10 \mu \mathrm{m}$; (in $\boldsymbol{J}) \boldsymbol{J}, \boldsymbol{L}, \boldsymbol{N}, \boldsymbol{P}, 50 \mu \mathrm{m}$.

proteoglycans (Christopherson et al., 2005; Kucukdereli et al., 2011; Pyka et al., 2011; Allen et al., 2012). Based on the roles of these astrocyte-derived ECM proteins, it is not entirely surprising that an ECM molecule like Collagen XIX could act in a paracrine fashion to regulate the assembly of perisomatic GABAergic synapses. What is unexpected, however, is that this synaptogenic cue is not generated by a synaptic partner or an adjacent astrocyte. Instead, it is generated by an adjacent interneuron. Thus, at a time when many studies are identifying interneuron-like roles for astrocytes in the brain (i.e., gliotransmission; Papouin et al., 

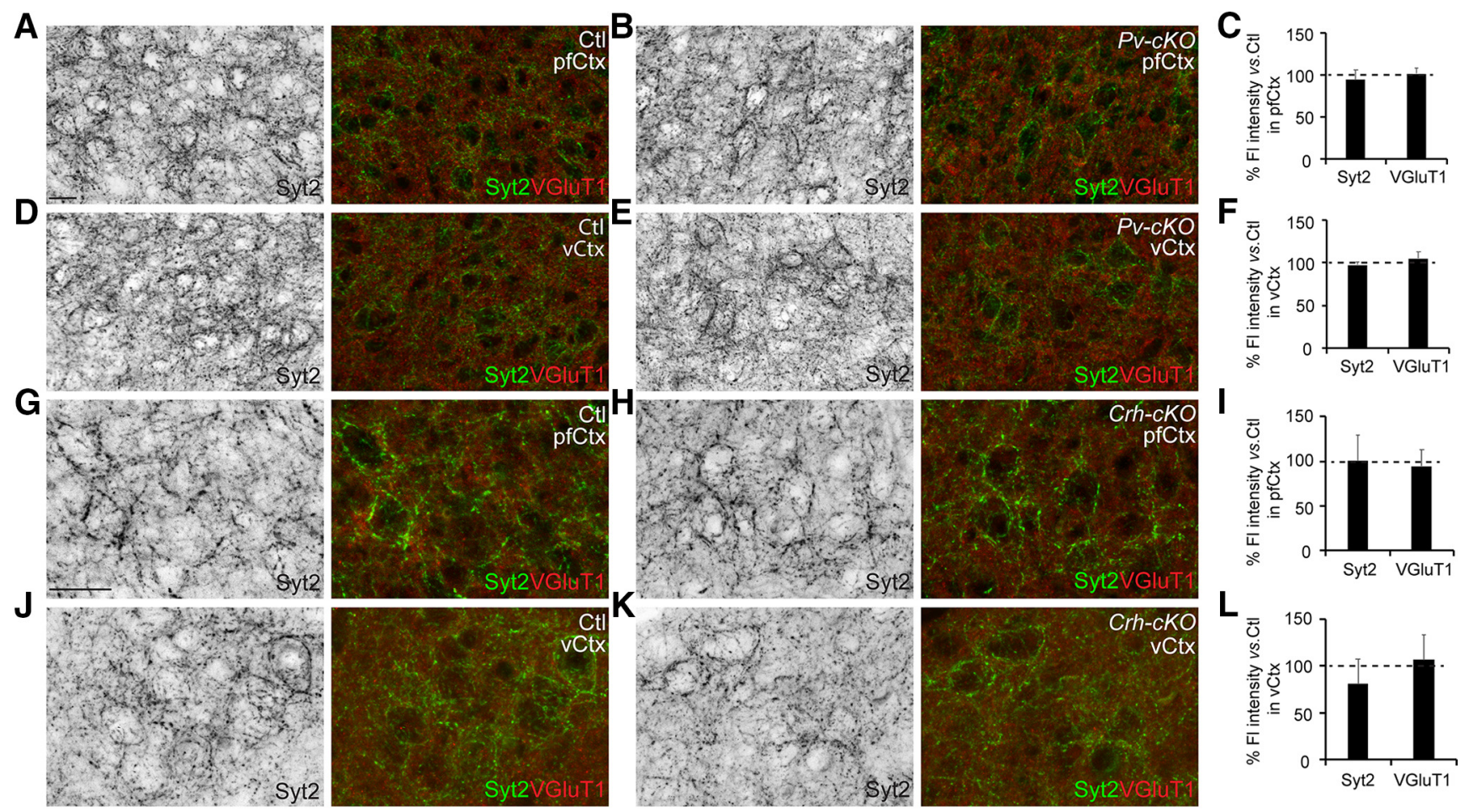

Figure 9. Loss of Collagen XIX from $\mathrm{PV}^{+}$or $\mathrm{CRH}^{+}$cells does not impair the formation of inhibitory nerve terminals in neocortex. $A, B, D, E$, Immunostaining for Syt2 and VGluT1 in layer $\mathrm{V}$ of prefrontal cortex (pfCtx) and visual cortex (vCtx) in P14 Col19a $7^{f / /}$ :.:PV-Cre (PV-cKO) mutants and littermate controls (Ctls). C, $F$, Mean fluorescent intensity of Syt2 and VGluT1 in layer V of pfCtx and vCtx in P14 PV-cKO and Ctl mice. Dashed line represents Ctl values. Data represent the mean \pm SD; $n=3 . \mathbf{G}, \boldsymbol{H}, \mathbf{J}, \boldsymbol{K}$, Immunostaining for Syt2 and VGluT1 in layer V of pfCtx and

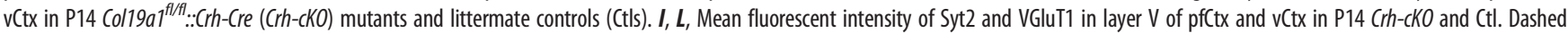
line represents Ctl values. Data represent the mean $\pm S D ; n=3$. Scale bar, $A, 20 \mu \mathrm{m}$.

2017; Fiacco and McCarthy, 2018; Savtchouk and Volterra, 2018), we have identified an astrocyte-like role for SST ${ }^{+}$interneurons in orchestrating GABAergic synapse formation.

\section{Matricryptins derived from collagen XIX regulate synapse formation}

Collagen XIX is an unconventional, nonfibrillar collagen whose expression is largely restricted to the brain postnatally (Sumiyoshi et al., 1997). Like many nonfibrillar collagens, Collagen XIX harbors a C-terminal noncollagenous domain that can be proteolytically shed as a matricryptin-a bioactive fragment of an ECM protein that exhibits distinct functions from the full-length matrix protein from which it was liberated (Ramont et al., 2007; RicardBlum and Salza, 2014). Outside of the nervous system, matricryptins derived from collagens, tenascins, perlecan, and osteopontin influence cell behavior by binding and signaling through integrin receptors (Petitclerc et al., 2000; Kalluri, 2003; Yokosaki et al., 2005; Borza et al., 2006; Saito et al., 2007; Poluzzi et al., 2014; Oudart et al., 2016; Ricard-Blum and Vallet, 2016). Within the nervous system, collagen-derived matricryptins exhibit conserved roles in orchestrating axon outgrowth, synapse formation, and synaptic plasticity in both vertebrate and invertebrate organisms (Ackley et al., 2001; Fox et al., 2007; Fox, 2008; Meyer and Moussian, 2009; Hilario et al., 2010; Latvanlehto et al., 2010; Su et al., 2012, 2016; Wang et al., 2014). Although not all of the mechanisms underlying matricryptin function in the nervous system have been fully elucidated, many induce their action by binding and signaling through integrin receptors, which themselves have long established roles in neural development and synaptogenesis (Park and Goda, 2016; Ferrer-Ferrer and Dityatev, 2018; Lilja and Ivaska, 2018). For example, endostatin, the matricryptin shed from Collagen XVIII, induces the assembly of cerebellar synapses by signaling through $\alpha 3 \beta 1$ integrins (Su et al., 2012). In the case of Collagen XIX, a small C-terminal matricryptin (termed $\mathrm{NC} 1[\mathrm{XIX}]$ ) is shed that is capable of binding and activating a number of aspartate-glycine-arginine (RGD)-dependent integrins (Oudart et al., 2015, 2016; Su et al., 2016). In the developing neocortex, $\mathrm{PV}^{+}$interneurons generate these same RGD-dependent integrins ( $\mathrm{Su}$ et al., 2016), suggesting that they are able to respond to the synaptogenic influence of $\mathrm{NC} 1[\mathrm{XIX}]$. In vitro experiments support this possibility, as NC1[XIX] triggers GABAergic synapse formation by binding and signaling through $\alpha 5 \beta 1$ integrins ( $\mathrm{Su}$ et al., 2016). Taken with the results demonstrated here, this strongly suggests that $\mathrm{SST}^{+}$ interneurons orchestrate perisomatic GABAergic synapse formation through the release of a synaptogenic, integrinbinding matricrpytin.

It is important to point out that Collagen XIX is not the only synaptogenic factor identified that contributes to the assembly and maturation of perisomatic GABAergic synapses in the developing neocortex. Neural cell adhesion molecule, neuroligin 2, L1, Slitrk3, and CXCL12 all contribute to the formation of this synapse (Guan and Maness, 2010; Takahashi et al., 2012; Woo et al., 2013; Liang et al., 2015; Maro et al., 2015; Wu et al., 2017). Why might so many cues be necessary for the assembly of this synapse? Synapse assembly is a multistep process in which priming factors first prepare synaptic partners to be competent to form a synapse, adhesion molecules then promote the interaction of presynaptic and postsynaptic membranes, inductive factors orchestrate the assembly of presynaptic and postsynaptic machinery, and destabilizing/stabilizing factors promote synaptic refinement or maturation (Waites et al., 2005). In vitro analyses 
suggest that Collagen XIX-derived matricryptins act early in this sequential process as priming factors that promote $\mathrm{PV}^{+}$interneurons to transcribe, translate, and traffic presynaptic components to developing nerve terminals ( $\mathrm{Su}$ et al., 2016). Many priming factors need not act locally at a synapse, but instead appear to act more diffusely, making specific neurons more competent to generate nerve terminals or become integrated into circuits (Waites et al., 2005). As such, $\mathrm{SST}^{+}$interneurons may not need to supply Collagen XIX (or NC1[XIX]) directly at sites of developing perisomatic GABAergic synapses, but instead can release it globally into the expansive extracellular space of the developing neocortex (Lehmenkühler et al., 1993; Korogod et al., 2015) or at sites of transient connectivity between $\mathrm{SST}^{+}$and $\mathrm{PV}^{+}$interneurons (Tuncdemir et al., 2016) for it to prime the assembly of feedforward inhibitory circuits.

\section{Reference}

Ackley BD, Crew JR, Elamaa H, Pihlajaniemi T, Kuo CJ, Kramer JM (2001) The NC1/endostatin domain of Caenorhabditis elegans type XVIII collagen affects cell migration and axon guidance. J Cell Biol 152:1219-1232.

Agmon A, Hollrigel G, O’Dowd DK (1996) Functional GABAergic synaptic connection in neonatal mouse barrel cortex. J Neurosci 16:4684-4695.

Albrecht A, Stork O (2012) Are NCAM deficient mice an animal model for schizophrenia? Front Behav Neurosci 6:43.

Allen NJ, Eroglu C (2017) Cell biology of astrocyte-synapse interactions. Neuron 96:697-708.

Allen NJ, Bennett ML, Foo LC, Wang GX, Chakraborty C, Smith SJ, Barres BA (2012) Astrocyte glypicans 4 and 6 promote formation of excitatory synapses via GluA1 AMPA receptors. Nature 486:410-414.

Ascoli GA, Alonso-Nanclares L, Anderson SA, Barrionuevo G, BenavidesPiccione R, Burkhalter A, Buzsaki G, Cauli B, Defelipe J, Fairén A, Feldmeyer D, Fishell G, Fregnac Y, Freund TF, Gardner D, Gardner EP, Goldberg JH, Helmstaedter M, Hestrin S, Karube F, et al. (2008) Petilla terminology: nomenclature of features of GABAergic interneurons of the cerebral cortex. Nat Rev Neurosci 9:557-568.

Belforte JE, Zsiros V, Sklar ER, Jiang Z, Yu G, Li Y, Quinlan EM, Nakazawa K (2010) Postnatal NMDA receptor ablation in corticolimbic interneurons confers schizophrenia-like phenotypes. Nat Neurosci 13:76-83.

Benes FM, Berretta S (2001) GABAergic interneurons: implications for understanding schizophrenia and bipolar disorder. Neuropsychopharmacology 25:1-27.

Biederer T, Kaeser PS, Blanpied TA (2017) Transcellular nanoalignment of synaptic function. Neuron 96:680-696.

Bonifazi P, Goldin M, Picardo MA, Jorquera I, Cattani A, Bianconi G, Represa A, Ben-Ari Y, Cossart R (2009) GABAergic hub neurons orchestrate synchrony in developing hippocampal networks. Science 326:14191424.

Borza CM, Pozzi A, Borza DB, Pedchenko V, Hellmark T, Hudson BG, Zent R (2006) Integrin alpha3beta1, a novel receptor for alpha3(IV) noncollagenous domain and a trans-dominant Inhibitor for integrin alphavbeta3. J Biol Chem 281:20932-20939.

Brooks JM, Carrillo GL, Su J, Lindsay DS, Fox MA, Blader IJ (2015) Toxoplasma gondii Infections Alter GABAergic Synapses and Signaling in the Central Nervous System. mBio 6:e01428-01415.

Bushong EA, Martone ME, Jones YZ, Ellisman MH (2002) Protoplasmic astrocytes in CA1 stratum radiatum occupy separate anatomical domains. J Neurosci 22:183-192.

Carrillo GL, Su J, Monavarfeshani A, Fox MA (2018) F-spondin Is Essential for Maintaining Circadian Rhythms. Front Neural Circuits 12:13.

Chattopadhyaya B, Di Cristo G, Higashiyama H, Knott GW, Kuhlman SJ, Welker E, Huang ZJ (2004) Experience and activity-dependent maturation of perisomatic GABAergic innervation in primary visual cortex during a postnatal critical period. J Neurosci 24:9598-9611.

Chen J, Kriegstein AR (2015) A GABAergic projection from the zona incerta to cortex promotes cortical neuron development. Science 350:554-558.

Christopherson KS, Ullian EM, Stokes CC, Mullowney CE, Hell JW, Agah A, Lawler J, Mosher DF, Bornstein P, Barres BA (2005) Thrombospondins are astrocyte-secreted proteins that promote CNS synaptogenesis. Cell 120:421-433.
Craig AM, Graf ER, Linhoff MW (2006) How to build a central synapse: clues from cell culture. Trends Neurosci 29:8-20.

Deacon RM (2006) Assessing nest building in mice. Nat Protoc 1:1117-1119.

De Marco García NV, Karayannis T, Fishell G (2011) Neuronal activity is required for the development of specific cortical interneuron subtypes. Nature 472:351-355.

Eroglu C, Barres BA (2010) Regulation of synaptic connectivity by glia. Nature 468:223-231.

Ferguson BR, Gao WJ (2018) PV interneurons: critical regulators of E/I balance for prefrontal cortex-dependent behavior and psychiatric disorders. Front Neural Circuits 12:37.

Ferrer-Ferrer M, Dityatev A (2018) Shaping synapses by the neural extracellular matrix. Front Neuroanat 12:40.

Ferriero DM, Sheldon RA, Messing RO (1994) Somatostatin enhances nerve growth factor-induced neurite outgrowth in PC12 cells. Brain Res Dev Brain Res 80:13-18.

Fiacco TA, McCarthy KD (2018) Multiple lines of evidence indicate that gliotransmission does not occur under physiological conditions. J Neurosci 38:3-13.

Fox MA (2008) Novel roles for collagens in wiring the vertebrate nervous system. Curr Opin Cell Biol 20:508-513.

Fox MA, Sanes JR (2007) Synaptotagmin I and II are present in distinct subsets of central synapses. J Comp Neurol 503:280-296.

Fox MA, Umemori H (2006) Seeking long-term relationship: axon and target communicate to organize synaptic differentiation. J Neurochem 97:12151231.

Fox MA, Sanes JR, Borza D-B, Eswarakumar VP, Fässler R, Hudson BG, John SWM, Ninomiya Y, Pedchenko V, Pfaff SL, Rheault MN, Sado Y, Segal Y, Werle MJ, Umemori H (2007) Distinct target-derived signals organize formation, maturation, and maintenance of motor nerve terminals. Cell 129:179-193.

Gonzalez B, Leroux P, Lamacz M, Bodenant C, Balazs R, Vaudry H (1992) Somatostatin receptors are expressed by immature cerebellar granule cells: evidence for a direct inhibitory effect of somatostatin on neuroblast activity. Proc Natl Acad Sci U S A 89:9627-9631.

Gonzalez-Burgos G, Lewis DA (2012) NMDA receptor hypofunction, parvalbumin-positive neurons, and cortical gamma oscillations in schizophrenia. Schizophr Bull 38:950-957.

Gonzalez-Burgos G, Hashimoto T, Lewis DA (2010) Alterations of cortical GABA neurons and network oscillations in schizophrenia. Curr Psychiatry Rep 12:335-344.

Gonzalez-Burgos G, Fish KN, Lewis DA (2011) GABA neuron alterations, cortical circuit dysfunction and cognitive deficits in schizophrenia. Neural Plast 2011:723184.

Griguoli M, Cherubini E (2017) Early correlated network activity in the hippocampus: its putative role in shaping neuronal circuits. Front Cell Neurosci 11:255.

Guan H, Maness PF (2010) Perisomatic GABAergic innervation in prefrontal cortex is regulated by ankyrin interaction with the L1 cell adhesion molecule. Cereb Cortex 20:2684-2693.

Hall AC, Lucas FR, Salinas PC (2000) Axonal remodeling and synaptic differentiation in the cerebellum is regulated by WNT-7a signaling. Cell 100:525-535.

Hilario JD, Wang C, Beattie CE (2010) Collagen XIXal is crucial for motor axon navigation at intermediate targets. Development 137:4261-4269.

Hrvatin S, Hochbaum DR, Nagy MA, Cicconet M, Robertson K, Cheadle L, Zilionis R, Ratner A, Borges-Monroy R, Klein AM, Sabatini BL, Greenberg ME (2018) Single-cell analysis of experience-dependent transcriptomic states in the mouse visual cortex. Nat Neurosci 21:120-129.

Hu JS, Vogt D, Sandberg M, Rubenstein JL (2017) Cortical interneuron development: a tale of time and space. Development 144:3867-3878.

Huang ZJ (2009) Activity-dependent development of inhibitory synapses and innervation pattern: role of GABA signalling and beyond. J Physiol 587:1881-1888

Huang ZJ, Kirkwood A, Pizzorusso T, Porciatti V, Morales B, Bear MF, Maffei L, Tonegawa S (1999) BDNF regulates the maturation of inhibition and the critical period of plasticity in mouse visual cortex. Cell 98:739-755

Huang ZJ, Di Cristo G, Ango F (2007) Development of GABA innervation in the cerebral and cerebellar cortices. Nat Rev Neurosci 8:673-686. 
Ivanova A, Signore M, Caro N, Greene ND, Copp AJ, Martinez-Barbera JP (2005) In vivo genetic ablation by Cre-mediated expression of diphtheria toxin fragment A. Genesis 43:129-135.

Ito-Ishida A, Miyazaki T, Miura E, Matsuda K, Watanabe M, Yuzaki M, Okabe S (2012) Presynaptically released Cbln1 induces dynamic axonal structural changes by interacting with GluD2 during cerebellar synapse formation. Neuron 76:549-564.

Jang S, Lee H, Kim E (2017) Synaptic adhesion molecules and excitatory synaptic transmission. Curr Opin Neurobiol 45:45-50.

Kaidanovich-Beilin O, Lipina T, Vukobradovic I, Roder J, Woodgett JR (2011) Assessment of social interaction behaviors. J Vis Exp. 48:2473.

Kalinovsky A, Boukhtouche F, Blazeski R, Bornmann C, Suzuki N, Mason CA, Scheiffele P (2011) Development of axon-target specificity of pontocerebellar afferents. PLoS Biol 9:e1001013.

Kalluri R (2003) Basement membranes: structure, assembly and role in tumour angiogenesis. Nat Rev Cancer 3:422-433.

Katz LC, Shatz CJ (1996) Synaptic activity and the construction of cortical circuits. Science 274:1133-1138.

Kepecs A, Fishell G (2014) Interneuron cell types are fit to function. Nature 505:318-326.

Korogod N, Petersen CC, Knott GW (2015) Ultrastructural analysis of adult mouse neocortex comparing aldehyde perfusion with cryo fixation. Elife 4:e05793.

Krienen FM, Goldman M, Zhang Q, Rosario RD, Florio M, Machold R, Saunders A, Levandowski K, Zaniewski H, Schuman B, Wu C, Lutservitz A, Mullally CD, Reed N, Bien E, Bortolin L, Fernandez-Otero M, Lin J, Wysoker A, Nemesh J, et al. (2019) Innovations in Primate Interneuron Repertoire. bioRXiv 709501. bioRXiv 709501. DOI:10.1101/709501.

Krook-Magnuson E, Armstrong C, Oijala M, Soltesz I (2013) On-demand optogenetic control of spontaneous seizures in temporal lobe epilepsy. Nat Commun 4:1376.

Kucukdereli H, Allen NJ, Lee AT, Feng A, Ozlu MI, Conatser LM, Chakraborty C, Workman G, Weaver M, Sage EH, Barres BA, Eroglu C (2011) Control of excitatory CNS synaptogenesis by astrocyte-secreted proteins Hevin and SPARC. Proc Natl Acad Sci U S A 108:E440-E449.

Latvanlehto A, Fox MA, Sormunen R, Tu H, Oikarainen T, Koski A, Naumenko N, Shakirzyanova A, Kallio M, Ilves M, Giniatullin R, Sanes JR, Pihlajaniemi T (2010) Muscle-derived collagen XIII regulates maturation of the skeletal neuromuscular junction. J Neurosci 30:12230-12241.

Lehmenkühler A, Syková E, Svoboda J, Zilles K, Nicholson C (1993) Extracellular space parameters in the rat neocortex and subcortical white matter during postnatal development determined by diffusion analysis. Neuroscience 55:339-351.

Lewis DA, Fish KN, Arion D, Gonzalez-Burgos G (2011) Perisomatic inhibition and cortical circuit dysfunction in schizophrenia. Curr Opin Neurobiol 21:866-872.

Lewis DA, Curley AA, Glausier JR, Volk DW (2012) Cortical parvalbumin interneurons and cognitive dysfunction in schizophrenia. Trends Neurosci 35:57-67.

Liang J, Xu W, Hsu YT, Yee AX, Chen L, Südhof TC (2015) Conditional neuroligin-2 knockout in adult medial prefrontal cortex links chronic changes in synaptic inhibition to cognitive impairments. Mol Psychiatry 20:850-859.

Liguz-Lecznar M, Urban-Ciecko J, Kossut M (2016) Somatostatin and somatostatin-containing neurons in shaping neuronal activity and plasticity. Front Neural Circuits 10:48.

Lilja J, Ivaska J (2018) Integrin activity in neuronal connectivity. J Cell Sci 131:jcs212803.

Lim L, Mi D, Llorca A, Marín O (2018) Development and functional diversification of cortical interneurons. Neuron 100:294-313.

Maro GS, Gao S, Olechwier AM, Hung WL, Liu M, Özkan E, Zhen M, Shen K (2015) MADD-4/punctin and neurexin organize C. elegans GABAergic postsynapses through neuroligin. Neuron 86:1420-1432.

Matsuda K, Miura E, Miyazaki T, Kakegawa W, Emi K, Narumi S, Fukazawa Y, Ito-Ishida A, Kondo T, Shigemoto R, Watanabe M, Yuzaki M (2010) $\mathrm{Cbln} 1$ is a ligand for an orphan glutamate receptor delta2, a bidirectional synapse organizer. Science 328:363-368.

Mayer C, Hafemeister C, Bandler RC, Machold R, Batista Brito R, Jaglin X, Allaway K, Butler A, Fishell G, Satija R (2018) Developmental diversification of cortical inhibitory interneurons. Nature 555:457-462.

Meyer F, Moussian B (2009) Drosophila multiplexin (Dmp) modulates motor axon pathfinding accuracy. Dev Growth Differ 51:483-498.
Missler M, Südhof TC, Biederer T (2012) Synaptic cell adhesion. Cold Spring Harb Perspect Biol 4:a005694.

Miyoshi G, Fishell G (2011) GABAergic interneuron lineages selectively sort into specific cortical layers during early postnatal development. Cereb Cortex 21:845-852.

Miyoshi G, Hjerling-Leffler J, Karayannis T, Sousa VH, Butt SJ, Battiste J, Johnson JE, Machold RP, Fishell G (2010) Genetic fate mapping reveals that the caudal ganglionic eminence produces a large and diverse population of superficial cortical interneurons. J Neurosci 30:1582-1594.

Mohajerani MH, Sivakumaran S, Zacchi P, Aguilera P, Cherubini E (2007) Correlated network activity enhances synaptic efficacy via BDNF and the ERK pathway at immature CA3 CA1 connections in the hippocampus. Proc Natl Acad Sci U S A 104:13176-13181.

Monavarfeshani A, Knill CN, Sabbagh U, Su J, Fox MA (2017) Region- and Cell-Specific Expression of Transmembrane Collagens in Mouse Brain. Front Integr Neurosci 11:20.

Moy SS, Nadler JJ, Perez A, Barbaro RP, Johns JM, Magnuson TR, Piven J, Crawley JN (2004) Sociability and preference for social novelty in five inbred strains: an approach to assess autistic-like behavior in mice. Genes Brain Behav 3:287-302.

Oudart J-B, Brassart-Pasco S, Vautrin A, Sellier C, Machado C, DupontDeshorgue A, Brassart B, Baud S, Dauchez M, Monboisse J-C, Harakat D, Maquart F-X, Ramont L (2015) Plasmin releases the anti-tumor peptide from the NC1 domain of collagen XIX. Oncotarget 6:3656-3668.

Oudart J-B, Doué M, Vautrin A, Brassart B, Sellier C, Dupont-Deshorgue A, Monboisse JC, Maquart FX, Brassart-Pasco S, Ramont L (2016) The antitumor NC1 domain of collagen XIX inhibits the FAK/PI3K/Akt/mTOR signaling pathway through $\alpha \mathrm{v} \beta 3$ integrin interaction. Oncotarget 7:1516-1528.

Owens DF, Kriegstein AR (2002) Is there more to GABA than synaptic inhibition? Nat Rev Neurosci 3:715-727.

Papouin T, Dunphy J, Tolman M, Foley JC, Haydon PG (2017) Astrocytic control of synaptic function. Philos Trans R Soc Lond B Biol Sci 372:20160154.

Park YK, Goda Y (2016) Integrins in synapse regulation. Nat Rev Neurosci 17:745-756.

Paz JT, Huguenard JR (2015) Microcircuits and their interactions in epilepsy: is the focus out of focus?. Nat Neurosci 18:351-359.

Pedersen CS, Sørensen DB, Parachikova AI, Plath N (2014) PCP-induced deficits in murine nest building activity: employment of an ethological rodent behavior to mimic negative-like symptoms of schizophrenia. Behav Brain Res 273:63-72.

Petitclerc E, Boutaud A, Prestayko A, Xu J, Sado Y, Ninomiya Y, Sarras MP Jr, Hudson BG, Brooks PC (2000) New functions for non-collagenous domains of human collagen type IV. Novel integrin ligands inhibiting angiogenesis and tumor growth in vivo. J Biol Chem 275:8051-8061.

Pfeffer CK, Xue M, He M, Huang ZJ, Scanziani M (2013) Inhibition of inhibition in visual cortex: the logic of connections between molecularly distinct interneurons. Nat Neurosci 16:1068-1076.

Pi HJ, Hangya B, Kvitsiani D, Sanders JI, Huang ZJ, Kepecs A (2013) Cortical interneurons that specialize in disinhibitory control. Nature 503:521-524.

Picardo MA, Guigue P, Bonifazi P, Batista-Brito R, Allene C, Ribas A, Fishell G, Baude A, Cossart R (2011) Pioneer GABA cells comprise a subpopulation of hub neurons in the developing hippocampus. Neuron 71:695709.

Poluzzi C, Casulli J, Goyal A, Mercer TJ, Neill T, Iozzo RV (2014) Endorepellin evokes autophagy in endothelial cells. J Biol Chem 289:16114-16128.

Pyka M, Wetzel C, Aguado A, Geissler M, Hatt H, Faissner A (2011) Chondroitin sulfate proteoglycans regulate astrocyte-dependent synaptogenesis and modulate synaptic activity in primary embryonic hippocampal neurons. Eur J Neurosci 33:2187-2202.

Ramont L, Brassart-Pasco S, Thevenard J, Deshorgue A, Venteo L, Laronze JY, Pluot M, Monboisse JC, Maquart FX (2007) The NC1 domain of type XIX collagen inhibits in vivo melanoma growth. Mol Cancer Ther 6:506514

Represa A, Ben-Ari Y (2005) Trophic actions of GABA on neuronal development. Trends Neurosci 28:278-283.

Ricard-Blum S, Salza R (2014) Matricryptins and matrikines: biologically active fragments of the extracellular matrix. Exp Dermatol 23:457-463. 
Ricard-Blum S, Vallet SD (2016) Matricryptins network with matricellular receptors at the surface of endothelial and tumor cells. Front Pharmacol 7:11.

Rossignol E, Kruglikov I, van den Maagdenberg AM, Rudy B, Fishell G (2013) CaV 2.1 ablation in cortical interneurons selectively impairs fastspiking basket cells and causes generalized seizures. Ann Neurol 74:209222.

Saito Y, Imazeki H, Miura S, Yoshimura T, Okutsu H, Harada Y, Ohwaki T, Nagao O, Kamiya S, Hayashi R, Kodama H, Handa H, Yoshida T, Fukai F (2007) A peptide derived from tenascin-C induces betal integrin activation through syndecan-4. J Biol Chem 282:34929-34937.

Sandberg M, Flandin P, Silberberg S, Su-Feher L, Price JD, Hu JS, Kim C, Visel A, Nord AS, Rubenstein JLR (2016) Transcriptional networks controlled by NKX2-1 in the development of forebrain GABAergic neurons. Neuron 91:1260-1275.

Savtchouk I, Volterra A (2018) Gliotransmission: beyond black-and-white. J Neurosci 38:14-25.

Schwaller B, Tetko IV, Tandon P, Silveira DC, Vreugdenhil M, Henzi T, Potier MC, Celio MR, Villa AE (2004) Parvalbumin deficiency affects network properties resulting in increased susceptibility to epileptic seizures. Mol Cell Neurosci 25:650-663.

Sgadò P, Dunleavy M, Genovesi S, Provenzano G, Bozzi Y (2011) The role of GABAergic system in neurodevelopmental disorders: a focus on autism and epilepsy. Int J Physiol Pathophysiol Pharmacol 3:223-235.

Shen K, Scheiffele P (2010) Genetics and cell biology of building specific synaptic connectivity. Annu Rev Neurosci 33:473-507.

Singh R, Su J, Brooks J, Terauchi A, Umemori H, Fox MA (2012) Fibroblast growth factor 22 contributes to the development of retinal nerve terminals in the dorsal lateral geniculate nucleus. Front Mol Neurosci 4:61.

Sommeijer JP, Levelt CN (2012) Synaptotagmin-2 is a reliable marker for parvalbumin positive inhibitory boutons in the mouse visual cortex. PLoS One 7:e35323.

Su J, Chen J, Lippold K, Monavarfeshani A, Carrillo GL, Jenkins R, Fox MA (2016) Collagen-derived matricryptins promote inhibitory nerve terminal formation in the developing neocortex. J Cell Biol 212:721-736.

Su J, Gorse K, Ramirez F, Fox MA (2010) Collagen XIX is expressed by interneurons and contributes to the formation of hippocampal synapses. J Comp Neurol 518:229-253.

Su J, Stenbjorn RS, Gorse K, Su K, Hauser KF, Ricard-Blum S, Pihlajaniemi T, Fox MA (2012) Target-derived matricryptins organize cerebellar synapse formation through $\alpha 3 \beta 1$ integrins. Cell Rep 2:223-230.

Sugino K, Hempel CM, Miller MN, Hattox AM, Shapiro P, Wu C, Huang ZJ, Nelson SB (2006) Molecular taxonomy of major neuronal classes in the adult mouse forebrain. Nat Neurosci 9:99-107.

Sumiyoshi H, Inoguchi K, Khaleduzzaman M, Ninomiya Y, Yoshioka H (1997) Ubiquitous expression of the alphal(XIX) collagen gene (Col19a1) during mouse embryogenesis becomes restricted to a few tissues in the adult organism. J Biol Chem 272:17104-17111.

Sumiyoshi H, Mor N, Lee SY, Doty S, Henderson S, Tanaka S, Yoshioka H, Rattan S, Ramirez F (2004) Esophageal muscle physiology and morphogenesis require assembly of a collagen XIX-rich basement membrane zone. J Cell Biol 166:591-600.

Suzuki K, Hayashi Y, Nakahara S, Kumazaki H, Prox J, Horiuchi K, Zeng M, Tanimura S, Nishiyama Y, Osawa S, Sehara-Fujisawa A, Saftig P, Yokoshima S, Fukuyama T, Matsuki N, Koyama R, Tomita T, Iwatsubo $\mathrm{T}$ (2012) Activity-dependent proteolytic cleavage of neuroligin-1. Neuron 76:410-422.

Takahashi H, Katayama K-I, Sohya K, Miyamoto H, Prasad T, Matsumoto Y, Ota M, Yasuda H, Tsumoto T, Aruga J, Craig AM (2012) Selective control of inhibitory synapse development by Slitrk3-PTPdelta trans-synaptic interaction. Nat Neurosci 15:389-398.
Taniguchi H, He M, Wu P, Kim S, Paik R, Sugino K, Kvitsiani D, Kvitsani D, Fu Y, Lu J, Lin Y, Miyoshi G, Shima Y, Fishell G, Nelson SB, Huang ZJ (2011) A resource of Cre driver lines for genetic targeting of GABAergic neurons in cerebral cortex. Neuron 71:995-1013.

Terauchi A, Johnson-Venkatesh EM, Toth AB, Javed D, Sutton MA, Umemori H (2010) Distinct FGFs promote differentiation of excitatory and inhibitory synapses. Nature 465:783-787.

Toth AB, Terauchi A, Zhang LY, Johnson-Venkatesh EM, Larsen DJ, Sutton MA, Umemori H (2013) Synapse maturation by activity-dependent ectodomain shedding of SIRP $\alpha$. Nat Neurosci 16:1417-1425.

Tremblay R, Lee S, Rudy B (2016) GABAergic interneurons in the neocortex: from cellular properties to circuits. Neuron 91:260-292.

Tronche F, Kellendonk C, Kretz O, Gass P, Anlag K, Orban PC, Bock R, Klein R, Schütz G (1999) Disruption of the glucocorticoid receptor gene in the nervous system results in reduced anxiety. Nat Genet 23:99-103.

Tuncdemir SN, Wamsley B, Stam FJ, Osakada F, Goulding M, Callaway EM, Rudy B, Fishell G (2016) Early somatostatin interneuron connectivity mediates the maturation of deep layer cortical circuits. Neuron 89:521535.

Uemura T, Lee SJ, Yasumura M, Takeuchi T, Yoshida T, Ra M, Taguchi R, Sakimura K, Mishina M (2010) Trans-synaptic interaction of GluRdelta2 and Neurexin through Cbln1 mediates synapse formation in the cerebellum. Cell 141:1068-1079.

Umemori H, Linhoff MW, Ornitz DM, Sanes JR (2004) FGF22 and its close relatives are presynaptic organizing molecules in the mammalian brain. Cell 118:257-270

Villette V, Guigue P, Picardo MA, Sousa VH, Leprince E, Lachamp P, Malvache A, Tressard T, Cossart R, Baude A (2016) Development of early-born $\gamma$-aminobutyric acid hub neurons in mouse hippocampus from embryogenesis to adulthood. J Comp Neurol 524:2440-2461.

Waites CL, Craig AM, Garner CC (2005) Mechanisms of vertebrate synaptogenesis. Annu Rev Neurosci 28:251-274.

Wamsley B, Fishell G (2017) Genetic and activity-dependent mechanisms underlying interneuron diversity. Nat Rev Neurosci 18:299-309.

Wang C-Z, Ma J, Xu Y-Q, Jiang S-N, Chen T-Q, Yuan Z-L, Mao X-Y, Zhang S-Q, Liu L-Y, Fu Y, Yu Y-C (2019) Early-generated interneurons regulate neuronal circuit formation during early postnatal development. Elife 8: e44649.

Wang T, Hauswirth AG, Tong A, Dickman DK, Davis GW (2014) Endostatin is a trans-synaptic signal for homeostatic synaptic plasticity. Neuron 83:616-629.

Wöhr M, Orduz D, Gregory P, Moreno H, Khan U, Vörckel KJ, Wolfer DP, Welzl H, Gall D, Schiffmann SN, Schwaller B (2015) Lack of parvalbumin in mice leads to behavioral deficits relevant to all human autism core symptoms and related neural morphofunctional abnormalities. Transl Psychiatry 5:e525.

Wonders CP, Anderson SA (2006) The origin and specification of cortical interneurons. Nat Rev Neurosci 7:687-696.

Woo J, Kwon S-K, Nam J, Choi S, Takahashi H, Krueger D, Park J, Lee Y, Bae JY, Lee D, Ko J, Kim H, Kim M-H, Bae YC, Chang S, Craig AM, Kim E (2013) The adhesion protein IgSF9b is coupled to neuroligin 2 via SSCAM to promote inhibitory synapse development. J Cell Biol 201:929944.

Wu PR, Cho KKA, Vogt D, Sohal VS, Rubenstein JLR (2017) The cytokine CXCL12 promotes basket interneuron inhibitory synapses in the medial prefrontal cortex. Cereb Cortex 27:4303-4313.

Xu Q, Cobos I, De La Cruz E, Rubenstein JL, Anderson SA (2004) Origins of cortical interneuron subtypes. J Neurosci 24:2612-2622.

Yokosaki Y, Tanaka K, Higashikawa F, Yamashita K, Eboshida A (2005) Distinct structural requirements for binding of the integrins alphavbeta6, alphavbeta3, alphavbeta5, alpha5beta1 and alpha9beta1 to osteopontin. Matrix Biol 24:418-427. 